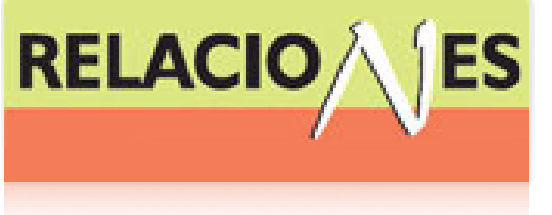

Relaciones. Estudios de historia y sociedad ISSN: 0185-3929

relacion@colmich.edu.mx

El Colegio de Michoacán, A.C

México

Torres Rodríguez, Alicia

Infraestructura hidráulica en Guadalajara para el abastecimiento de agua potable: el caso de sustentabilidad en las galerías filtrantes de Guadalajara

Relaciones. Estudios de historia y sociedad, vol. XXXIV, núm. 136, 2013, pp. 317-357

El Colegio de Michoacán, A.C

Zamora, México

Disponible en: http://www.redalyc.org/articulo.oa?id=13729711011

- Cómo citar el artículo

Número completo

- Más información del artículo

- Página de la revista en redalyc.org

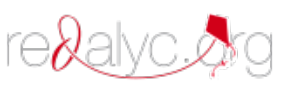

Sistema de Información Científica

Red de Revistas Científicas de América Latina, el Caribe, España y Portugal Proyecto académico sin fines de lucro, desarrollado bajo la iniciativa de acceso abierto 


\title{
Infraestructura hidráulica en Guadalajara para el abastecimiento de agua potable: el caso de sustentabilidad en las galerías filtrantes de Guadalajara
}

\author{
Alicia Torres Rodríguez \\ UNIVERSIDAD DE GUADALAJARA
}

En el presente artículo se analiza la construcción de la infraestructura hidráulica para el abastecimiento de agua a la ciudad de Guadalajara y su continuidad, específicamente, la primera obra que permitió el abastecimiento de agua de manera colectiva; las galerías filtrantes, que basan su funcionamiento en aguas phreáticas y subterráneas. A su vez se describe la región hidrológica de Guadalajara y la importancia de los actores sociales que participaron en su construcción, así como la tecnología utilizada, que hicieron posible llevar agua a la ciudad. Por otra parte, se da seguimiento, en el tiempo, de las galerías filtrantes y su impacto en las zonas de extracción, sustentabilidad y permanencia de éstas como fuente de abastecimiento para la ciudad, considerando la riqueza de sus acuíferos, los cuales han sido olvidados o no tomados en cuenta por cuestiones políticas y económicas.

(Región hidrológica, galerías filtrantes, abastecimiento de agua, sustentabilidad)

\section{INTRODUCCIÓN}

T a ciudad de Guadalajara se funda por los espańoles en el valle de Atemajac ${ }^{1}$ en el siglo Xvi, debido a la presencia del río San Juan de Dios y otros afluentes de agua, como: la Campana, el Chocolate, la Hermita de Zapopan, de Zoquipan, los manantiales de Mexicalzingo, Agua Azul (que nutrían gran parte del caudal del

*Atorres59@gmail.com

${ }^{1}$ A esta zona geohidrológica se le conoce con el nombre de Atemajac-Tesistán, cuenta con una densidad aproximada de 1 a 1.45 pozos en promedio por kilómetro cuadrado (INEGI 2000) 
río de San Juan de Dios), así como otros más ${ }^{2}$. El aprovechamiento de los ríos, arroyos, manantiales y aguas subterráneas cercanos al núcleo urbano de la ciudad de Guadalajara permitieron, desde su instalación (1542), el abastecimiento de agua y sufragar la demanda de sus habitantes. A pesar de ello, uno de los grandes problemas que enfrentaron para conducir el agua a la ciudad fue su ubicación con respecto a las fuentes de abastecimiento, dado a que éstas se encontraban en niveles más bajos que el centro de la ciudad, se necesitaba elevarlas para conducirlas y poder abastecer a su población. Desde ese tiempo y hasta ahora ha representado un problema constante, pese a contar con diversas fuentes de abastecimiento de agua superficial y subterránea, la ciudad ha sufrido la falta de este recurso por falta de tecnología adecuada para elevar o extraer y conducir el agua, además del factor económico para realizar las obras necesarias que permitan abastecer el crecimiento urbano e industrial de la ciudad y su zona metropolitana.

Las fuentes de abastecimiento de agua (superficiales y subterráneas) que formaban el primer cinturón de la región hidrológica de Guadalajara sufrieron serias transformaciones, de ser ríos y manantiales abundantes, fueron reducidos a ríos de aguas negras o desaparecidas bajo la construcción de una vía pública. ${ }^{3}$ En cuanto a las aguas subterráneas, éstas se encuentran sobreexplotadas, no tienen la posibilidad de recargarse a causa de que muchos de sus espacios han sido pavimentados como consecuencia del crecimiento urbano, debido a la idea de que progreso es igual a calles pavimentadas, sin

${ }^{2}$ La capacidad de infiltración de los suelos, la conducción de agua por debajo de estos es abundante por lo que hay ríos subterráneos desde Tesistán por el norponiente, hasta Toluquilla en el sur. Por el norte está la zona de la barranca (que se conoce por dos nombres: Oblatos y Huentitán) y el río Santiago; por el oeste está el bosque de la Primavera, el cual incrementa la recarga de agua subterránea debido a que recoge el agua de lluvia que va a dar de manera natural hacia la zona de Atemajac del valle. Véase Ana Rosa González García, "Estrategias y control del agua en Guadalajara, siglo xIx. El caso de las industrias textiles", en Salvador Peniche Camps y Manuel Gúzman Arroyo, coords., Estudios de la cuenca del río Santiago: un enfoque multidisciplinario, Cucea, Universidad de Guadalajara, 2011, localizado el 10 de enero de 2013 en Biblioteca Virtual de Derecho, Economía y Ciencias Sociales. http:/www.eumed.net/libros-gratis/2010f/859/ESTRATEGIAS\%20 Y\%20CONTROL\%20DEL\%20AGUA\%20EN\%20GUADALAJARA.htm

${ }^{3}$ Véase González García, 2011. 
considerar la recarga de los mantos freáticos que alimentan el sistema de pozos, que vulnera la sustentabilidad de los mismos y limita a la ciudad de estos recursos para su abastecimiento a largo plazo.

A la fecha sigue presentándose la escasez recurrente de agua, no sólo por el crecimiento poblacional y urbano, también por el aumento de la instalación de la industria, así como la contaminación y sobrexplotación que sufren las fuentes de abastecimiento, con lo cual se da la necesidad de recurrir a fuentes cada vez más lejanas y con un mayor gasto económico por el tipo de infraestructura hidráulica que se tiene que construir.

La Zona Metropolitana de Guadalajara (ZMG) cuenta actualmente con tres sistemas de abastecimiento de agua: Pozos de Tesistan y Toluquilla, Chapala-Guadalajara y el de presas La Zurda-Calderón, de la cual sólo se ha construido su primera etapa, el resto del proyecto implica que se tendría que bombear el agua dado que el río Verde se encuentra por debajo del nivel de la ciudad -casi 600 metros-(Torres 2009).

El objetivo de este trabajo es describir y analizar la construcción de la infraestructura hidrológica para el abastecimiento de agua a la ciudad de Guadalajara y su continuidad, en especial, la primera obra que permitió el abastecimiento de agua de manera colectiva; las galerías filtrantes ${ }^{4}$-que basan su funcionamiento en aguas phreáticas ${ }^{5}$ y subterráneas-, así como la sustentabilidad y permanencia de éstas como fuente de abastecimiento para la ciudad, al considerar la riqueza de sus acuíferos, los cuales han sido olvidados o no tomados en cuenta por cuestiones políticas y económicas.

Este documento se divide en tres apartados: el primero hace la descripción de la región hidrológica de Guadalajara que da cuenta

${ }^{4}$ Sobre este tema, Relaciones. Estudios de Historia y Sociedad publicó de Christopher S. Beekman, Phil C. Weigand y John J. Pint, "El qanat de La Venta: sistemas hidráulicos de la época colonial en el centro de Jalisco”, vol. xvi, núms. 63/64, Zamora, El Colegio de Michoacán, 1995 (nota del editor).

${ }^{5}$ Gabriel Castaños hacia una diferencia esencial entre sus obras y las de Buzeta: clasificaba las obras antiguas como "aprovechamiento de las aguas phreáticas", y Castaños de "captación de aguas subterráneas". El método de Buzeta llamado "aprovechamiento de las aguas phreáticas", es decir, el sistema consiste en practicar un gran número de pozos, al fondo de los cuales afluye el líquido del cono de desecación y, en seguida, conducir todas las aguas a un punto central (Castańos 1895). 
de las cuencas que conforman la región y los acuíferos que se encuentran dentro de ella, que han sido de la mayor importancia para el abastecimiento de la ciudad desde su instalación en el Valle de Atemajac. El segundo trata sobre la construcción de la infraestructura hidráulica, los actores sociales que participaron en ella, la problemática y tecnología utilizada, centrándonos principalmente, como ya se ha señalado anteriormente, en las galerías filtrantes de la ciudad, con las cuales se logra llevar agua a los habitantes de Guadalajara, y da inicio al modelo de abastecimiento de agua colectiva. Finalmente, se hará el análisis de la construcción de las galerías filtrantes y su relación con las fuentes de abastecimiento de agua utilizadas para cubrir la demanda de la ciudad, así como la sustentabilidad durante su existencia e impacto en las zonas de extracción; considerando que algunas de ellas se encuentran aún en funcionamiento, aunque la mayoría ya no son utilizadas para el consumo humano, sino para el riego de parques y jardines de la gran zona metropolitana en que se transformó la ciudad de Guadalajara.

\section{Región hidRológica de GuAdalajara E INSTALACión DE La CiUdad en el valle de Atemajac}

El primer cinturón de la región hidrológica de Guadalajara está conformado por los ríos San Juan de Dios, Atemajac y los manantiales de Agua Blanca, San Andrés, San Ramón, Mexicaltzingo y Agua Azul, así como una serie de arroyos y manantiales, los cuales se encontraban en las inmediaciones de la ciudad de Guadalajara (plano 1), abarcaba una superficie de aproximadamente 70 hectáreas en 1542 (Martínez 1988), además de las aguas subterráneas que eran aprovechadas por medio de pozos o norias construidos en el interior de las viviendas (Jiménez 1992).

El estudio para la utilización de los recursos hídricos se realizó hacia los diferentes puntos cardinales de la ciudad, sin embargo, la mayor parte de las fuentes de abastecimiento de agua presentaron problemas para su aprovechamiento, dados los niveles más bajos en que se encontraban, así como la falta de tecnología para elevarlos al nivel del centro de la ciudad, al ser su principal fuente de abasteci- 


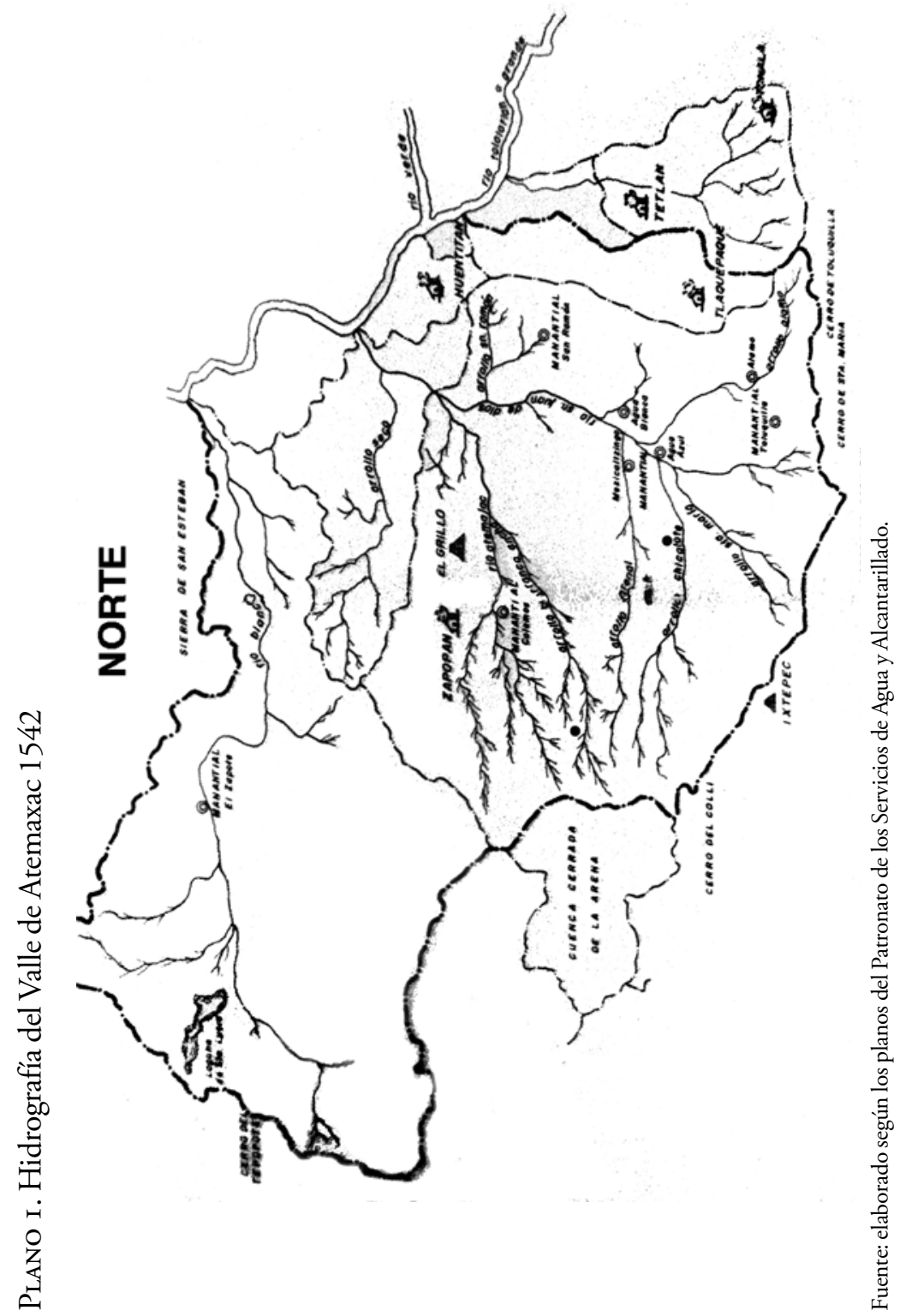


miento la perforación de pozos y/o norias particulares, además del río San Juan de Dios antes río Blanco (Castaños 1895; Jiménez 1992).

Desde 1597 se intentó por primera vez traer el agua de Los Colomos, como lo seńala López Cotilla (1842), sin embargo, se hallaba en un nivel más bajo que el centro de la ciudad, por lo que se continuó con la búsqueda de un afluente que pudiera ser conducido con menores costos, para lo cual se realizaron varios estudios de los cuerpos de agua que la circundan, sin resultados adecuados como se muestran en el cuadro 1 .

CuAdro i. Fuentes consideradas para llevar agua a la ciudad de Guadalajara 1600-1703

\begin{tabular}{lll}
\hline $\begin{array}{l}\text { Fuente de } \\
\text { abastecimiento }\end{array}$ & Año
\end{tabular}

Los Colomos

159726 varas* más bajas que el piso de la ciudad, entro a la ciudad por tagea de cal y canto. Se trajo bordeando al pueblo de Mezquitan hasta la espalda del Convento de Santo Domingo. Esta obra duro poco por disminución del agua o las aguas estaba más bajas que la tagea.

Río del Alamo 1641 El agua se encuentra bajo el nivel de Guadalajara al igual que las del cerro de Toluquilla

Arroyo Agua Blanca 1675 Ubicado entre el oriente y sur de la ciudad a un cuarto de legua ${ }^{* *}$ de distancia que formaba un riachuelo que corría de oriente a norte, se realizó un canal pero duro poco.

Manantiales del cerro de Toluquilla, los de San Ramón, Los Colomos y río Grande de Tololotlan

Las aguas del contorno de Zapopan
1675 La de Toluquilla era necesario barrenar desde la orilla de la ciudad hasta el cerro, la del río de Tololotlan se calculó veinte leguas de rodeo muy costosas, las de San Ramón estaban a 16 varas (13.92 metros) de altura sobre la ciudad, pero se consideraba de mala calidad y a más de una legua (Cornejo 1942).

1703 Se encontraron a 16 varas más bajas que el plano de la ciudad de Guadalajara y a dos leguas de la ciudad y se tenían que pasar por barrancas muy anchas y profundas por lo que saldrían costosas. 
Cuadro i. Fuentes consideradas para llevar agua a la ciudad de Guadalajara 1600-1703 (continuación)

\begin{tabular}{lrl}
\hline $\begin{array}{l}\text { Fuente de } \\
\text { abastecimiento }\end{array}$ & Año & \multicolumn{1}{c}{ Problemática presentada } \\
\hline $\begin{array}{l}\text { El agua de Tesistan } \\
\text { Cuyutlan }\end{array}$ & 1703 & La orografía implicaba elevados costos. \\
San Agustín & 1703 & $\begin{array}{l}\text { Se encontraba muy lejos de la ciudad. } \\
\text { San Andrés }\end{array}$ \\
1703 & $\begin{array}{l}\text { Se encontraba lomas antes de llegar a la ciudad. } \\
\text { ciudad pero se consideraba de male cala calidad y } \\
\text { un derrotero largo y poco firme. }\end{array}$ \\
\hline
\end{tabular}

Fuente: Elaboración propia con datos de López Cotilla 1842; Camacho 1886; Cornejo Franco 1942. * Medida de longitud que se usaba en distintas regiones de España con valores diferentes, que oscilaban entre 768 y $912 \mathrm{~mm}$. Real Academia Española, localizado el 11 de enero de 2013, http://lema.rae.es/drae/srv/search?id=0JhE054vLDXX2JYCA50r.

** La legua es una antigua unidad de longitud que expresa la distancia que una persona o un caballo pueden andar en una hora, según el tipo de terreno predominante en cada país o según la conveniencia estatal, la palabra legua abarca distancias que van de los 4 a los $7 \mathrm{~km}$, siendo las más frecuentes las leguas que se encuentran en la media de tales extremos equivalente a 20 mil pies castellanos (5572.7 metros), aunque su longitud varía según los países (4,190 metros en México o 6,600 metros en Brasil) e incluso según las regiones.

Como se muestra en el cuadro 1, Guadalajara se localizaba dentro de una región hidrológica con grandes posibilidades de ser abastecida de manera suficiente, sin embargo, las condiciones y características de los recursos hídricos y la orografía de la región no le permitían contar con dicho recurso de manera constante y por largo plazo.

A inicios del siglo XviII (1731) se hace traer a fray Pedro Antonio Buzeta, lego de la orden de los franciscanos, maestro de Arquitectura, ya conocido por la introducción que hizo del agua subterránea en la ciudad de Veracruz de 1723-1724, quien aprovechó los estudios y los proyectos previos, además de realizar el reconocimiento de los alrededores de la población coincidió con los resultados anteriores y concluyó que la opción más viable era el aprovechamiento de las aguas subterráneas ubicadas al poniente de la ciudad, teniendo como indicador los pozos ubicados en esa zona, los cuales contenían agua suficiente y de excelente calidad a una profundidad media de once varas. Por lo que consideraba que 
no había agua alguna en mejores condiciones para entrar a la ciudad. Surgió con ello la propuesta del aprovechamiento de aguas a través de la construcción de galerías filtrantes para la captación y conducción del agua a Guadalajara (Camacho 1886; Cornejo Franco 1942).

En el estudio de los recursos hídricos, tanto superficiales, como subterráneos, existentes en el contorno de la ciudad, se siguieron analizando las aguas de la región y cómo podrían ser llevadas con diferentes técnicas a Guadalajara como: las aguas de Los Colomos (1777) por el oidor Zagarzurrieta; del Astillero, del Alamo, las fuentes de Zapote y Buelles, presa antigua, la de la Huerta o Camichin, (1787); Mexicalzingo (1801) por el oidor Camacho; río Grande-río Santiago- San Ramón, Los Colomos (1830). En 1862, los manantiales de San Andrés y San Ramón se estudian para llevar las aguas al Hospicio y al barrio de San Juan de Dios y en 1889 y 1890 las filtraciones del Colli, vía las galerías. Otros más fueron el río Osorio, Aguas del Astillero, Arroyo del Arenal, arroyo de la Campana, arroyo de Chochocastli, arroyo el Aguacero que se reúnen con el de Colomos, sin embargo, la falta de conocimientos de las capas geológicas, configuración topográfica del terreno, así como la tecnología existente y los grandes costos que significaba tomarla de otras fuentes, se mantuvo la consideración que lo más viable seguían siendo las aguas subterráneas del poniente de la ciudad, aunque deficientes y sujetas a grandes oscilaciones, significaba la opción más adecuada en ese momento de acuerdo a los estudios realizados por fray Pedro Antonio Buzeta en 1731.

En 1895, Castaños hace una clasificación de las aguas (varias de ellas seńaladas en los estudios realizados por Buzeta en 1731) en dos grupos al oriente y poniente del río San Juan de Dios según el depósito donde se podrían llevar sus aguas, pero que dan cuenta de su abundancia, pero también de su limitación para ser utilizadas en el abastecimiento de agua a la ciudad. Señalaba que el suelo poroso al poniente y oriente de la ciudad permite gran absorción del agua pluvial y que esta agua almacenada por las lluvias se renueva anualmente, además de las aguas de las vertientes de los cerros que al sureste limitan el valle y se derraman sobre el mismo terreno e 
incrementan la cantidad de agua disponible, factibles de ser utilizadas para ser llevadas a la ciudad. En el cuadro 2 se muestra la agrupación de las aguas realizada por Castańos.

Cuadro 2. Ubicación, cantidad y calidad de las fuentes de abastecimiento de agua de Guadalajara según el deposito donde se podrían llevar (1895)

\section{Primer grupo para ser depositado en el reservatorio oriente}

Manantiales del Rosario Situado a 2.60 m Debajo de la Plaza de Armas, calidad sospechosa.

Manantiales del Agua Da de 2,000,000 a 1,200,000 litros en 24 hrs. Azul Nivel poco inferior a los anteriores, calidad poco confiable.

Manantial del Alamo Escaso caudal, insuficiente para la ciudad, situado a 14.21 metros, sobre la Plaza de Armas y a 5 km, el agua es potable.

Manantiales de San Pedro

La calidad es buena, cantidad insuficiente y partida en varios puntos, distante a $5 \mathrm{~m}$ de la plaza de la capital.

Manantial de Tonalá Abundante y suficientemente elevado, a $13 \mathrm{~km}$ de distancia, surte al pueblo del mismo nombre, situado a la caída oriental del terreno, hacia la barranca del río Grande.

Manantiales de San

Se encuentra a $16.43 \mathrm{~m}$ sobre la Plaza de Armas, Andrés su importancia es mediana e insuficiente, puede ser aprovechada y surtir el barrio de San Juan de Dios.

Manantial de San

De poca importancia, abastece al Hospital de esta Ramón ciudad y una parte del Barrio de San Juan de Dios.

Segundo grupo al poniente para ser depositado cerca de la Garita del Carmen

Manantiales de Toluquilla y de San Sebastian
Juntos dan un caudal de 150 litros por segundo se encuentra a una altura de $4.22 \mathrm{~m}$ inferior a la Plaza de Armas y su distancia es de 13 a $14 \mathrm{~km}$, la calidad de las aguas es buena, pero implican un fuerte gasto (en la falda sur del cerro del Cuatro, sus aguas corresponden al valle de Santa Cruz, se halla separado del valle de Guadalajara, por el sur desde los Cerrillos hasta los cerros del Gachupin y de Santa Ana). 
Cuadro 2. Ubicación, cantidad y calidad de las fuentes de abastecimiento de agua de Guadalajara según el deposito donde se podrían llevar (1895) (continuación)

Segundo grupo al poniente para ser depositado cerca de la Garita del Carmen

Manantiales los Pueblitos

Manantiales los Colomos

Manantial de los Chorros

Río Atemajac

Manantiales de los Colomitos
A $9 \mathrm{~km}$ al noroeste, se hallan situados a $120 \mathrm{~m}$ sobre la Plaza de Armas importancia muy corta y sólo podrían aprovecharse como auxiliares.

Se encuentra a $14.25 \mathrm{~m}$ debajo de la Plaza de Armas, insuficiente importancia por sí solos, se consideran más adelante como afluentes del río Atemajac, su caudal es de 20 a 30 litros y se hallan a $6 \mathrm{~km}$.

Su altura es de $9.78 \mathrm{~m}$, abajo de la Plaza de Armas, la cantidad puede estimarse en 12 litros de régimen variable.

Las numerosas y pequeñas vertientes que nacen en el terreno barrancoso al suroeste del pueblo de Zapopan y entre las cuales figuran los Colomos, La Campana, La Tinaja, El Chocolate, El Aguacero y algunos otros que brotan de las barranquillas laterales, vienen reunidas a formar un riachuelo que lleva el nombre de río Atemajac, cuyo gasto unido al agua de los chorros pueden estimarse en 500 litros, éstas alimentan la Presa de las Fábricas de Atemajac, el Batán, La Experiencia y el Salvador. Su situación es $15 \mathrm{~m}$ inferior a la Plaza de Armas y su volumen considerable.

Se hallan a $4 \mathrm{~km}$ al norte de la ciudad y a $50 \mathrm{~m}$ abajo de la Plaza de Armas, debajo de ella su caudal es sólo de 6 litros.

Fuente: Elaboración propia con datos de los apuntes del Ing. Gabriel Castańos, 1895.

Como se puede observar en el cuadro 2, las fuentes de abastecimiento con que contaba la ciudad de Guadalajara se conforman en su mayoría por manantiales, lo que da cuenta de la gran capacidad de absorción del agua de lluvia por el tipo de suelo, permitía su almacenamiento natural al oriente y poniente de la ciudad, sin embargo, por sí solos, éstos eran insuficientes y su conducción era costosa para abastecer a la zona urbana de Guadalajara. Además la 
falta de recursos y tecnología para elevar sus aguas al nivel del centro de la ciudad hacían inaccesible el agua, ocasionando con ello su constante escasez en medio de la abundancia.

Se consideraba que para el crecimiento de Guadalajara se tendría como reserva elevar las aguas de Toluquilla o del río de Atemajac y alimentar las galerías colectoras de las aguas subterráneas, sin olvidar al río Grande y la laguna de Chapala. Ya López Cotilla (1831) señalaba: "no podrá dudar ninguno que conozca las inmediaciones de Guadalajara y que haya observado la multitud de manantiales que en todas direcciones la circundan" (Estrada Godínez 2008).

Hablar entonces de la escasez de agua como la ausencia de ésta, no sería preciso, dadas las diversas fuentes de agua que aquí se señalan y conforman el primer cinturón de la región hidrológica de Guadalajara. $^{6}$

\section{LAS GALERÍAS FILTRANTES PARA EL ABASTECIMIENTO de agua A la CiUdad de Guadalajara}

Desde la instalación de la ciudad de Guadalajara en el valle de Atemajac en los márgenes del río San Juan de Dios, se destinó para su abasto público el agua del nacimiento llamada Agua Blanca. Se propuso poner una fuente (pila) de agua en la plaza mayor en 1597 probablemente financiada por los vecinos (Jímenez 1992), en este mismo año entró el agua de los manantiales de Los Colomos por ta-

${ }^{6}$ La Región Hidrológica de Guadalajara se conforma con los recursos hidrológicos localizados en un radio de alrededor de 50 kilómetros a partir del centro de la ciudad, la cual se dividió en tres cinturones hidrológicos, considerando cada uno de ellos a partir de los usos de los diferentes cuerpos de agua a través de la construcción de infraestructura hidráulica, la que permite la conducción de los recursos hídricos a la ciudad. Dichos cinturones hidrológicos se forman con recursos superficiales y subterráneos. La construcción de las obras de infraestructura para conducir el agua a la ciudad, no presenta una continuidad espacial ni temporal, es decir, que éstos no fueron construidos del centro a la periferia de manera continua en la región ni en el tiempo. A partir de los cinturones hidrológicos se conforman los sistemas de abastecimiento de agua: sistema de pozos profundos, forma parte del primer y segundo cinturón hidrológico; sistema ChapalaSantiago, forma parte del tercer y segundo cinturón hidrológico; y el sistema de presas La Zurda-Calderón y el proyecto de la presa de Arcediano se encuentran en el segundo cinturón (Torres Rodríguez 2009). 
jea de fábrica de cal y canto hasta el convento de Santo Domingo, obra que duró poco, por lo que la ciudad se seguía abasteciendo del río de San Juan de Dios y de pozos. López Cotilla señalaba que el río San Juan de Dios quedó para las bestias, para baño y lavaderos de la clase pobre (Cornejo 1942), sin embargo en 1641 se introduce agua de este río, repartiendo el gasto entre los vecinos conforme a derechos (Oidor Camacho 1886).

Otros intentos de llevar agua a la ciudad fue la introducción de las aguas de Toluquilla, logrando traerlas por zanja hasta la esquina del convento de Santa Teresa en tan escasa cantidad, que se abandonó el proyecto. A lo largo de este periodo se sigue autorizando de manera continua el producto del estanco de vinos de coco y mezcal (1726); se agregan las licencias de saca de ganado (1730); el abasto de carnes (1735) para la aplicación en las obras del agua (Cornejo 1942).

Finalmente se da inicio a la introducción del agua a la ciudad de Guadalajara (1731) a través de la construcción de las galerías filtrantes o minas de agua a partir del aprovechamiento de los veneros y manantiales ubicados al poniente de la ciudad por fray Pedro Antonio Buzeta (Castaños 1895). Los frailes eran formados en universidades y en medios de cultura material avanzados, además de aportar creencias y rituales religiosos, planeaban y ejecutaban soberbios conventos, así como acueductos, recios canales y minas de agua, significan estas grandes obras de ingeniería hidráulica, como la de Veracruz y Guadalajara, que fueron realizadas para conducir el agua de sus lejanos manantiales y aguas subterráneas a los centros de población, tal es el caso fray Juan de Alameda, del padre Tembleque y de fray Pedro Buzeta (Torre 2003).

La galería filtrante o qanat según Palerm (2004) es una técnica milenaria originada en el cercano oriente para llevar a la superficie aguas subterráneas por gravedad. Se caracteriza por alumbrar con técnica minera aguas ocultas en abanicos aluviales, se señala que existe variación en el tipo de aguas subterráneas captadas: la captación de aguas subálveas, la excavación de un túnel y su profundización siguiendo un manantial previamente existente. Los tres casos están presentes en México y podemos añadir un cuarto que corresponde a los socavones construidos para desaguar minas. La caracte- 
rización de qué es un qanat tiene cierta diversidad, pero consiste esencialmente en un acueducto subterráneo (pozo horizontal o bocamina horizontal) que penetra en un acuífero y conduce el agua por gravedad a la superficie. La captación del agua subterránea en el acueducto puede darse por filtración de las paredes o de un manantial en su piso (o techo). La longitud del acueducto subterráneo está relacionada con la distancia entre el lugar de captación del agua y su conducción hasta hacerla aflorar por gravedad a la superficie. Es típico que el acueducto subterráneo cuente, a distancias periódicas, con respiraderos (lumbreras) que sirven también para introducirse en él y darle mantenimiento.

El proyecto de galerías filtrantes que planteo Buzeta en 1731 para abastecer a la capital fue por el método llamado "Aprovechamiento de las aguas phreáticas", cuyo sistema consiste en practicar gran número de pozos, al fondo de los cuales afluye el líquido del cono de desecación y enseguida se conducen todas las aguas a un punto central. Con lo que se conseguiría gran cantidad de agua poniéndo a todos a un mismo nivel y conducirla a la ciudad en abundancia y permanencia, además de ser las aguas mejores de los contornos de la ciudad (Castaños 1895).

Con la construcción realizada por Buzeta dio inicio la modificación del modelo de abastecimiento de agua a la ciudad: de particular, pozos o norias, a colectiva, a través de algunas fuentes públicas, iglesias, conventos, Palacio Real, Cárcel y algunas casas particulares, a partir de las galerías filtrantes que permitieron mayor afluente de agua con la captación de varios veneros y su conducción a través de tres líneas de galerías filtrantes, pero que además marcó, en casi doscientos años, el uso de las aguas freáticas y subterráneas en la ciudad de Guadalajara:

Castaños (1895) señaló en su informe que las obras de Buzeta no fueron de grandes proporciones (6,950 varas) ni de un plan general, ya que sólo tenían que satisfacer las necesidades de aquella época, pues, la ciudad contaba con alrededor de 8,000 y 9,000 familias. Aún no se lograba llevar el agua directamente a los hogares, considerando que gran parte de la población se abastecía de los pozos privados y muy poca cantidad bastaba para el servició público, además 
Cuadro 3. Infraestructura de las galerías filtrantes de Buzeta (1731-1740)

Obras Características de la obra

Galerías poniente

Galerías norte

Galería intermedia o del Centro (Camino Real)

Tagea

Cajas de agua

(o repartidoras)

Escalera de piedra "El Caracol"
A dos mil quinientas varas de distancia de la ciudad y en ochocientas y más de éstas hacia el poniente, se abrieron lumbreras de cincuenta en cincuenta varas, de seis de circunferencia para minar de unas a otras en las ochocientas, a las que ocurrirían los veneros de agua que juntos se habían de conducir a la ciudad, sangrándolas con suficiente altura en el paraje que pareciese más a propósito del resto de las mil trescientas varas. De siete cuartas de alto y dos tercias de ancho, de modo que pudiera entrar un hombre para revisar y dar mantenimiento y recibiese todos los manantiales que ocurrieren a las dos líneas y reconocidos en el poniente de la ciudad, por no haber manantiales se reuniría el agua en un tanque o agua cerrada, y se formaría la tagea.

De sur a norte, con lumbreras de cincuenta varas, comunicadas por minas en el plan que se hallase el agua, cortándose de este modo muchos veneros dispersos por el llano, y a todos aparte de los manantiales arriba expresados, que todos debían venir a juntarse en la otra línea del poniente en las minas de estas dos se había de formar una tagea.

Se construyó después de las dos primeras con el fin de aumentar la cantidad de agua.

De cal y piedra en el plan y lados con buen macizo que no se desprendiese, y así se trataría de conducir hasta la altura proporcionada para formar las fuentes, fabricando en este sitio otra arca, donde se partiesen las cañerías de caños, bien gruesos y macizos.

Siete varas de diámetro, catorce de profundidad, sobre más de un suelo bien macizo y enlosado con escaleras de caracol para bajar.

Con gradas de cantería y antepecho de ladrillo y sirviendo como regulador de abundancia y escasez, por el tiempo que tarda en llenarse y como expurgador para que de allí pase limpia el agua.

Fuente: Elaboración propia con datos del oidor Camacho, 1886. Castańos, 1895 y Cornejo Franco 1942. 
Plano 2. Conducción del agua a la ciudad de Guadalajara, 1741

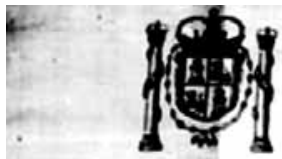

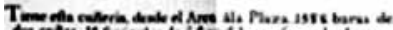

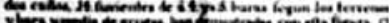

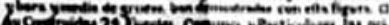

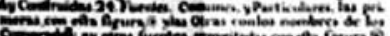

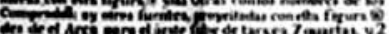

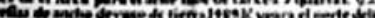

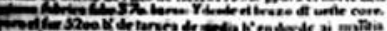

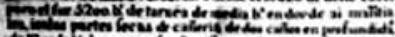

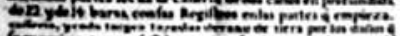

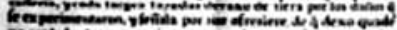

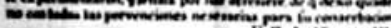
Fiphisarnerter

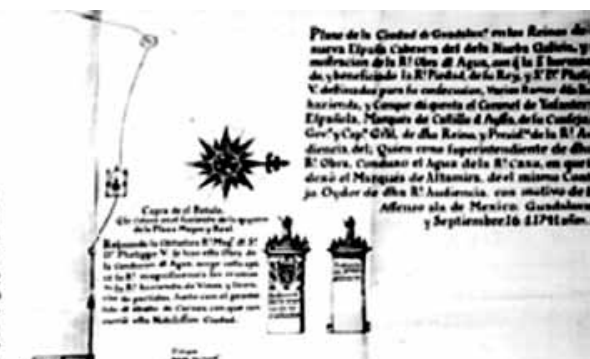

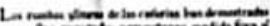

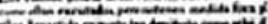

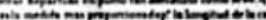

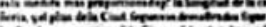

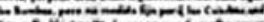

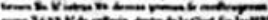

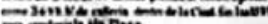

$\square \square \square \square$

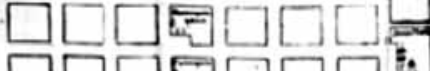

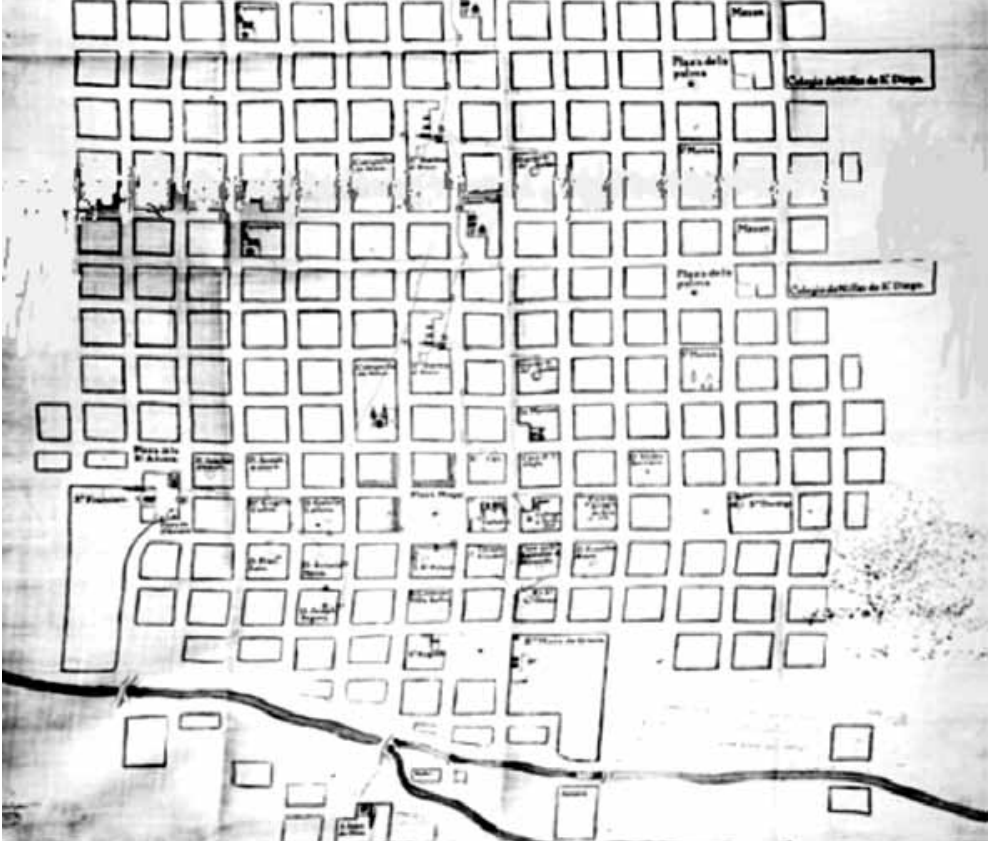

Fuente: Mapas ubicados en la Biblioteca Pública del Estado de Jalisco "Juan José Arreola”, Archivo de la Real Audiencia de Guadalajara. 
Plano 3. Plano iconográfico de la ciudad de Guadalajara

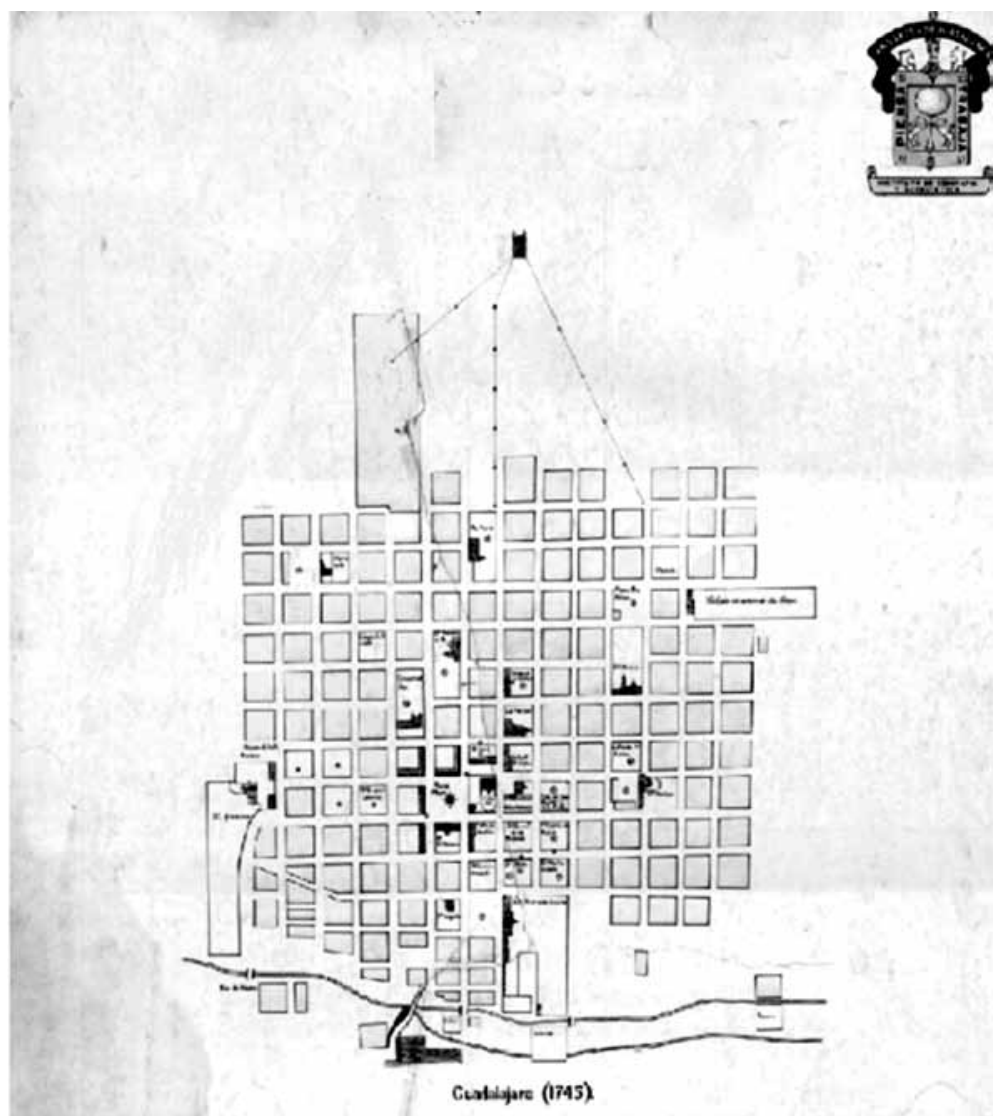

Fuente: Mapas ubicados en la Biblioteca Pública del Estado de Jalisco "Juan José Arreola”, Archivo de la Real Audiencia de Guadalajara.

que ésta no tenía ningún costo. En 1740, se consiguió la distribución de este recurso a partir de pilas o fuentes ubicadas en conventos e iglesias y algunos espacios públicos: Plaza Mayor, plazuela de las religiosas Carmelitas, Palacio Real, Cárcel de Corte, plazuela de San Agustín, convento de San Francisco y posteriormente el convento de Santo Domingo, como se muestra en los siguientes planos (2 y 3 ) de 1741 y 1745 de la ciudad de Guadalajara (Jiménez, 1992). 
El sistema de agua por galerías filtrantes de Buzeta abasteció a la ciudad de Guadalajara a lo largo de ocho años aunque con algunas variaciones pero con buen caudal. La infraestructura de las galerías fue dañada debido a los temblores (1750) que sufrió la ciudad disminuyendo su volumen, por lo que se pensó en sustituirla con otras obras en 1778, verificando nuevamente la posibilidad de introducir el agua de Los Colomos, pero finalmente se reparan las cañerías de la obra existente, sin dejar la busqueda de otras fuentes de abastecimiento (oidor Camacho 1886; López Cotilla 1842).

A finales del siglo Xvin continuaba siendo la obra de Buzeta la principal fuente de abastecimiento de la ciudad, a partir de la caja de agua salían tres cańerías: la primera de naranjo, por enfrente del oriente para la fuente de la Plaza Mayor y Mercedes: la segunda por del norte de media naranja para la fuente de la plazuela de Santo Domingo: y la tercera para la del sur de un limón, para el convento de padres carmelitas: que desde la caja hasta la esquina poniente-sur de San Agustín, había diez y siete alcantarillas y sólo corrían a la fuente de la Plaza Mayor y San Agustín y las Mercedes de Palacio. Además de las carceles Jesús María, Santa María de Gracia. De la misma caja hasta la plazuela de Santo Domingo, había once alcantarillas hacia la plazuela de Santo Domingo y la merced de religiosas de Santa Mónica, al igual que el anterior grupo con mucha escasez (oidor Camacho 1886).

Estas obras se siguieron ampliando por el oidor don Francisco Camacho, el cual mandó hacer otra atarjea al lado de la antigua, se renovó la caja que ya existía y se fabricó en ambas un registro para la distribución del agua, incrementando el flujo de agua a la ciudad. A su vez mandó levantar un plano del acueducto registrando la obra de Buzeta, así como las ampliaciones que él había realizado en 1798, la cual constaba de tres líneas de pozos (véase plano 4).

Éstas llegaron a tener una extensión de 9,651 varas $(8,396.37$ metros) en 1796 y para 1895 se incrementaron hasta $20 \mathrm{~km}$, es decir de cinco a seis leguas, su mayor crecimiento fue en el siglo XVIII. Castaños (1895) señalaba en su informe: que fuera de las obras que construyera Buzeta y de las que llevó adelante el oidor Camacho; los trabajos se habían limitado a prolongar las galerías y una vez con- 
Cuadro 4. Galerías filtrantes de Buzeta ampliadas por el oidor Francisco Camacho (1796)

\begin{tabular}{lcc}
\hline Galerías & Caracteristicas & Longitud \\
\hline $\begin{array}{l}\text { Galería del norte o Los } \\
\text { Colomos }\end{array}$ & 17 pozos & 1,600 varas $(1,392 \mathrm{~m})$ \\
$\begin{array}{l}\text { Galería del centro o } \\
\text { Camino Real }\end{array}$ & 19 pozos & 2,000 varas $(1,740 \mathrm{~m})$ \\
Galería del sur o Santa & 26 pozos & 5,400 varas $(8,396.37 \mathrm{~m})$ \\
Ana &
\end{tabular}

Fuente: Elaboración propia con datos de Castaños 1895.

seguido algún aumento de agua se abandonaban sin consolidación alguna, dejando correr el líquido por el simple piso de la galería tortuosa y estrecha, con pendientes variables, donde el curso se entorpece o desvía con el menor obstáculo, por lo que no se puede estimar el caudal de agua que son capaces de reunir las antiguas obras, además por la gran cantidad que se pierde por infiltraciones y desvíos en su trayectoria como se observa en el plano 4, mandado a elaborar por el oidor Camacho.

Por otra parte, se mencionaba que no se siguieron las indicaciones que dejó Buzeta, quien señaló que se debía prolongar la línea de Los Colomos, no obstante, se crecieron hacia Santa Ana, quizás para llegar a los manantiales de Mexicaltzingo. En 1801 se inicia la obra de estos manantiales pero sin éxito, dado lo costosa que resultaba (López Cotilla 1842). En 1803 se trata nuevamente de utilizar sus aguas por el intendente comandante militar de Guadalajara José de la Cruz, usando a los indios de los pueblos vecinos, los prisioneros de la cárcel y la tropa competente al mando, pero no lo logró, se señalaba que el agua no era de tan buena calidad como las que venían de la obra de Buzeta (Jímenez 1992).

Para 1811 se seguía insistiendo en esta fuente para sumar sus aguas al abastecimiento de Guadalajara -dada su cercanía a la ciudad-, elevando sus aguas, obra que no se concluye por sus altos costos, así como por el uso de caños de barro que no resistieron la presión necesaria para alcanzar las partes altas de la población. Di- 
Plano 4. Plano del acueducto de Guadalaxara

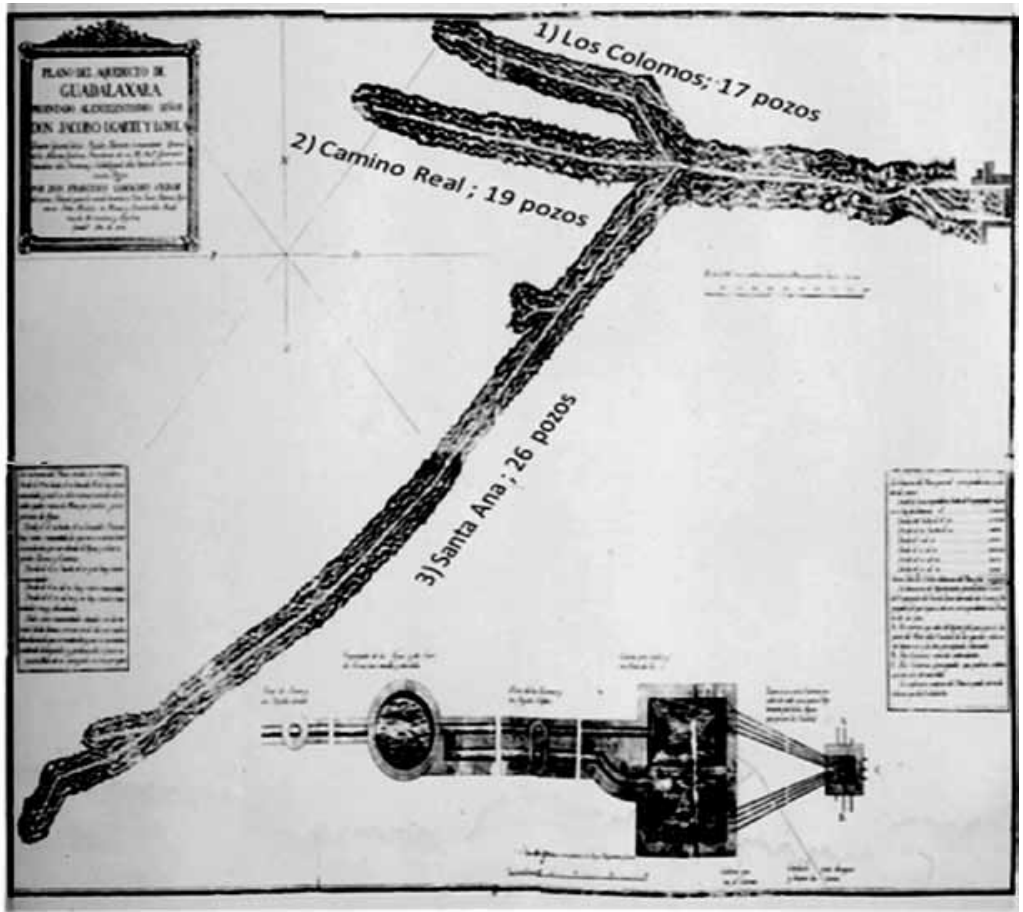

Fuente: Mapas ubicados en la Biblioteca "Manuel Rodríguez Lapuente” del Centro Universitario de Ciencias Sociales y Humanidades de la Universidad de Guadalajara.

cha obra fue abandonada después de algunos años de servicio. En 1830 se continuó tratando de poner la obra a funcionar sin ningún efecto, en esta ocasión, por la demora de su reparación, además del fuerte gasto que seguía implicando este proyecto, por lo que se siguió extendiendo la obra de Buzeta.

También se propuso introducir las aguas del río Grande (río Santiago) por don Samuel I. Trant, pero se abandonó la idea porque el nivel al que se encontraba con respecto a la ciudad (15 metros abajo) y los elevados costos seguían siendo un obstáculo para llevar sus aguas a Guadalajara, al igual que la de los manantiales de San Ramón y Los Colomos (Castaños 1895). 
No obstante, en 1835 se pensó nuevamente en las aguas de San Ramón, manantial ubicado al oriente del río San Juan de Dios, sin resultados (Castaños 1895). No obstante, los problemas que presentaba la ciudad para el abastecimiento de agua a sus habitantes, los ríos Blanco y Atemajac (en Zapopan) estaban siendo utilizados para el desarrollo de la industria: en 1840 se instala la fábrica Atemajac (textil) y el Batan (papel), ambas sobre el cauce del río Atemajac, y la fábrica la Escoba sobre el río Blanco en 1843 (textil, hilaza y manta) (González García 2010).

Después de concluir la época colonial tras la lucha de los insurgentes, cambia la forma de administrar los recursos hídricos, ya que era la Corona quien autorizaba el gasto de los impuestos obtenidos del vino de coco y mezcal para apoyar la búsqueda y construcción de infraestructura para la introducción del agua en el caso de la ciudad de Guadalajara.

En 1845, las obras eran construidas por el municipio y por los gobernadores del estado en su etapa de vida independiente. Es el caso del munícipe Manuel Escorza que introdujo en este año el agua de un manantial situado al sur de la caja de agua conocida como "El Caracol de Buzeta", aumentando con ello el suministro a 54 litros por segundo. También seguía siendo una fuente de abastecimiento la perforación de pozos particulares.

Para 1853, inicia sus trabajos la fábrica la Experiencia con la elaboración de textiles e hilaza, utilizando el motor hidraúlico, esta industria también se ubica sobre el margen del río Atemajac en busca y control del preciado líquido al igual que la ciudad (González García). En 1862 se hicieron algunas obras sobre el manantial San Ramón, que dieron como resultado abastecer con ellas el Hospicio y el barrio de San Juan de Dios, obras semejantes en principio a las de Buzeta, fueron realizadas por el obispo Diego Aranda. Es entonces este sistema de galerías filtrantes fundamental en la vida de Guadalajara ${ }^{7}$ (Castańos 1895).

${ }^{7}$ Los documentos revisados no hacen mención de la construcción de las galerías filtrantes de San Rafael y San Andrés ubicados también al oriente del río San Juan de Dios, éstos se encuentran representados en el plano 5, como parte de los acueductos que surten de agua a la ciudad de Guadalajara y formados por orden del C. gobernador del estado 
En cuanto a la calidad del agua que venía de los tres rumbos (poniente, norte y sur) se calificaba como excelente, especialmente la del Colli (sur), pues se decía que tenía un sabor más agradable, además de los resultados de los análisis realizados en 1880 , señalaban que tenían: "Temperatura, $21^{\circ}$ grados centígrados; color ligeramente opalina; olor, ninguno; sabor, fresco y muy agradable; embotellada se conserva durante varios meses. Disuelve perfectamente el jabón, cuece y ablanda muy bien las legumbres y no ataca en lo más mínimo el plomo de las cañerías" (Villa Gordoa 1980).

Lo anterior no se podía decir de los pozos de las casas particulares, pues se consideraba el agua no potable a excepción de los pozos que existían en el barrio de la parroquia del Santuario de Guadalupe y algunos del Carmen cuya agua se consideraba mejor que la del Colli (Villa Gordoa 1980, 45). Para estas fechas se habían incrementado el número de pilas o fuentes públicas, pues se contaba con alrededor de 39, distribuidas en diferentes puntos de la ciudad como se muestra en el cuadro 5 .

Otro de los cambios importantes, en el abastecimiento de agua a la ciudad, fue en las formas de extracción, conducción y distribución de agua a partir del uso de la bomba movida por vapor -sistema Worthington- y la tubería de fierro de $25.5 \mathrm{~cm}$ de diámetro interior, se logró captar más agua de las fuentes antiguas como el Agua Azul y el Colli (1887), se hizo llegar los caudales a un tanque situado en el interior de la penitenciaría del estado y, de ahí, a la antigua caja existente cerca de "El Caracol" (Martínez 1988).

Guadalajara cuenta en 1890 con alrededor de 107,000 habitantes, por lo que se consideraba necesario contar con más recursos hídricos para abastecer a su población, para ello se contrata, por el gobernador Luis C. Curiel, al ingeniero Gabriel Castańos (originario de Guadalajara) a partir de 1893. Castaños realizó una exploración de las obras de Buzeta, así como de la situación topográfica de Guadalajara y los manantiales brotantes ubicados en los terrenos al

Gral. Luis Curiel en 1902. Obras que me ha sido posible constatar a partir de los recorridos de campo, así como por las entrevistas realizadas a trabajadores del Sistema Intermunicipal de Agua Potable y Alcantarillado (SIAPA) en 2008. 
Cuadro 5. Pilas o fuentes para la distribución del agua en la ciudad de Guadalajara 1880

\begin{tabular}{lccc}
\hline Ubicación & $\begin{array}{c}\text { Número } \\
\text { de pilas o } \\
\text { fuentes }\end{array}$ & Ubicación & $\begin{array}{c}\text { Número } \\
\text { de pilas o } \\
\text { fuentes }\end{array}$ \\
\hline $\begin{array}{l}\text { Palacio de gobierno } \\
\text { Palacio de gobierno en Prisciliano }\end{array}$ & 4 & Atrio del San Agustín & 1 \\
$\begin{array}{l}\text { Sánchez } \\
\text { Sto. Domingo }\end{array}$ & 1 & Templo de Jesús María & 1 \\
$\begin{array}{l}\text { Sta. Mónica } \\
\text { Convento del Carmen }\end{array}$ & 1 & Mercado de Venegas & 1 \\
Penitenciaría & 4 & $\begin{array}{c}\text { Plazuela de las Nueve } \\
\text { Frente a la Alameda }\end{array}$ & 1 \\
$\begin{array}{l}\text { Plazuela del Hospicio } \\
\begin{array}{l}\text { Plazuela de San Felipe, conocida } \\
\text { como de San Jorge }\end{array}\end{array}$ & 1 & Plazuela de los Burros & 1 \\
$\begin{array}{l}\text { En la Hojita, dos cuadras al poni- } \\
\text { ente del Santuario }\end{array}$ & 1 & Jardín de San Francisco & 2 \\
$\begin{array}{l}\text { Caja de agua } \\
\text { Parque Alcalde }\end{array}$ & 4 \\
\hline
\end{tabular}

Fuente: Villa Gordoa 1980.

oriente y poniente de la ciudad, señalando que estos manantiales eran renovados cada ańo por las lluvias, almacenándose en la gran masa que forma la toba pomosa, son las más importantes las que se encuentran al poniente de la ciudad, se extienden desde el pueblo de Zapopan hasta las alturas que al sur cierran el valle de Guadalajara y, al oriente, en el lomerío que desde San Ramón se extiende hasta San Pedro y los Cerrillos. En las dos partes las aguas se presentan a una altura dominante respecto de la ciudad de Guadalajara (Castaños 1895).

Castańos en su análisis de las obras de conducción de agua a Guadalajara, señalaba que fuera de las galerías filtrantes construidas por Buzeta y la continuidad de ellas por el oidor Camacho, los tra- 
bajos para el abastecimiento de agua a Guadalajara se limitaron a su mantenimiento en los momentos de escasez, sin su consolidación, se dejó el simple piso de la galería tortuosa y estrecha, con pendientes variables, donde el curso se entorpecía o desviaba con el menor obstáculo, propiciando las pérdidas de agua por infiltraciones, por lo que resultaba difícil calcular la cantidad de agua que producían estas obras, al tener como único dato la cantidad que llegaba al " $\mathrm{Ca}$ racol”, que era de 480,000 litros durante 24 horas. El 29 de septiembre que se hizo la entrega fue de 6.2 litros por segundo, es decir, 535,680 por día, contra 907,200 litros por día a fines de agosto de 1893 , por lo que se estimaba que las aguas subterráneas eran suficientes para surtir a Guadalajara (Castaños 1895).

$\mathrm{Al}$ considerar lo anterior, el ingeniero Castańos advertía la existencia de un almacenamiento notable que estaba en el nivel dominante de la ciudad y era factible conducir el agua a través de galerías, por lo que se planeó detener el deslizamiento y filtración del agua de lluvia a partir de construir obstáculos sobre la capa impermeable a través de cortes en la primera capa arcillo-arenosa, así como diques que detuvieran el curso rápido de las aguas pluviales que las hicieran permanecer sobre el terreno natural para ser absorbidas por las arenas y tobas pomosas aumentando con ello su almacenamiento, a esto se sumaban las aguas de los escurrimientos de los cerros que al suroeste limitaban al valle (Castaños 1895).

De acuerdo con Castaños,

la nueva obra para llevar más agua a la ciudad se basaría en el principio de construcción y aprovechamiento de las aguas de lluvia soterradas en la región de Guadalajara pero a diferentes niveles de su almacenamiento que las realizadas por Buzeta. Por lo que la construcción de nuevas galerías filtrantes se hicieron sobre la capa impermeable y en el cuerpo de la toba pomosa, en el trazo de la curva de nivel número 79 , a la cota de 38 metros sobre la plaza de Armas, cerrando desde un punto próximo al puerto de Santa María, al sur y hasta las barrancas de Zapopan al norte, ya que la parte del valle se extiende hacia los cerros del Colli y de Santa Ana que detienen el curso de las aguas que se deslizan sobre dicha capa, en virtud del declive que hacia el noreste se tiene (Castaños 1896). 


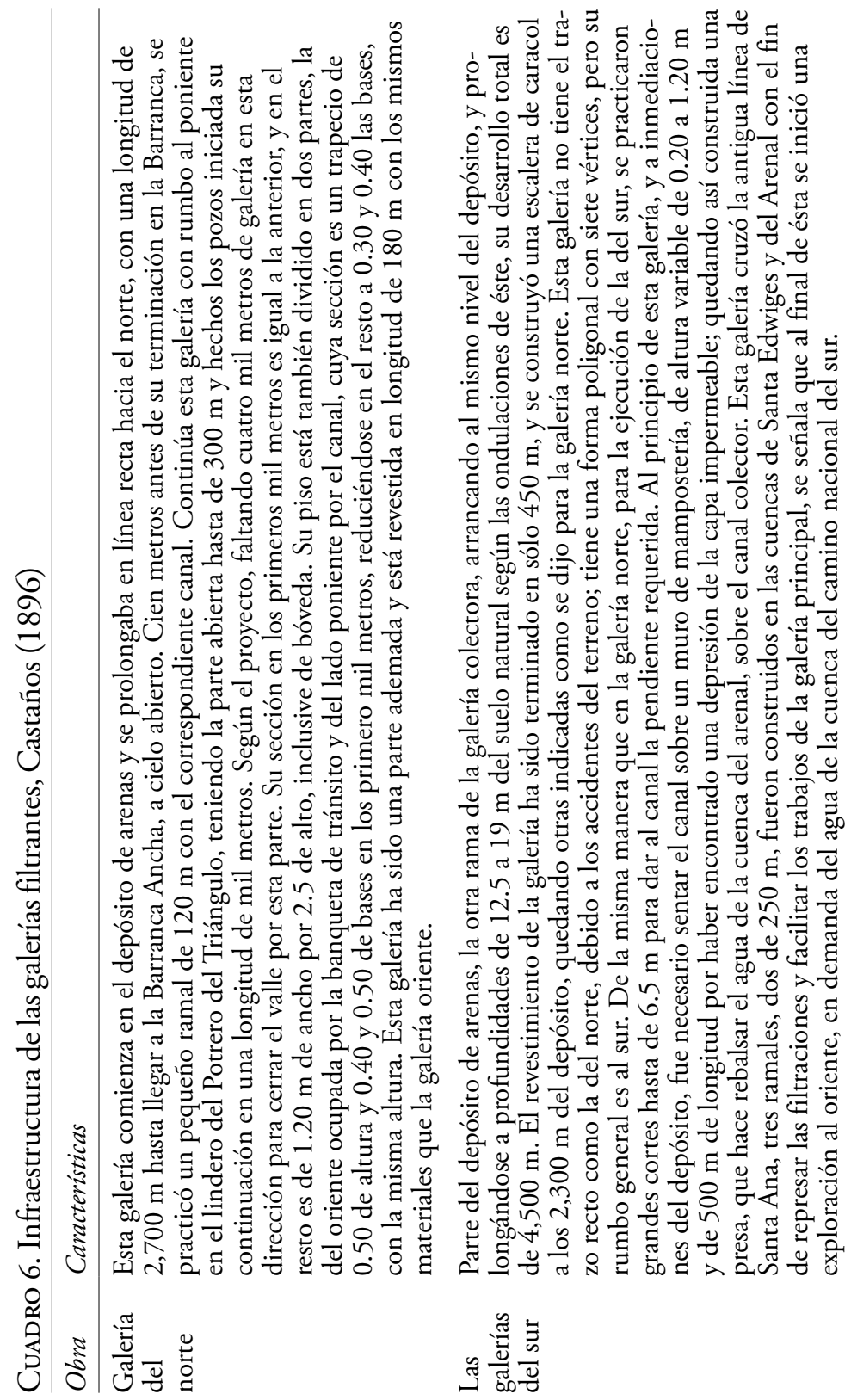




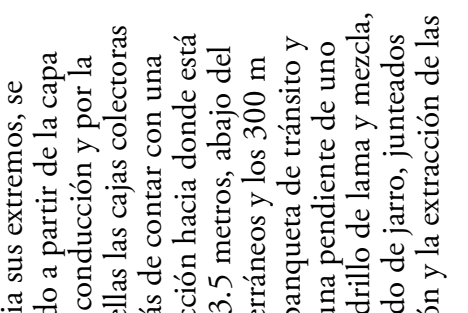

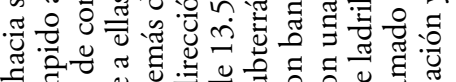

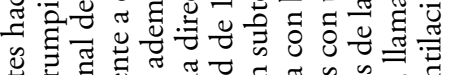

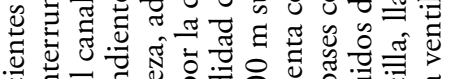

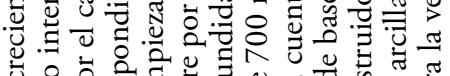

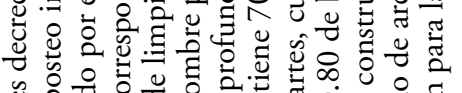

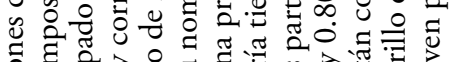

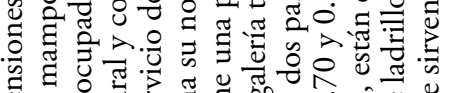

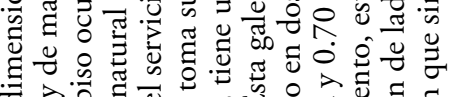

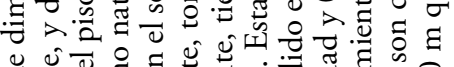

等

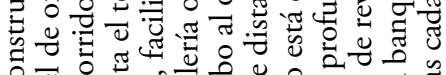

8.

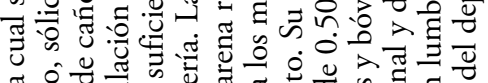

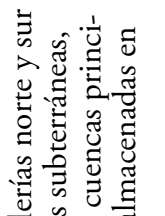

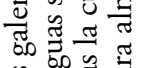

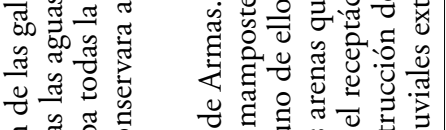

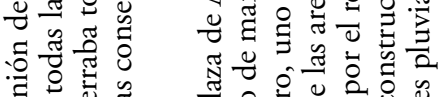

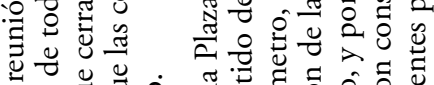

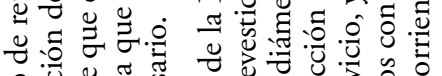

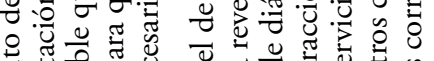

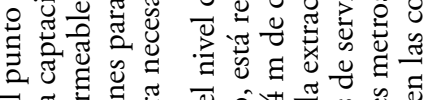

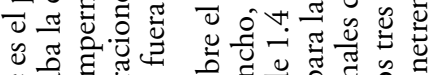

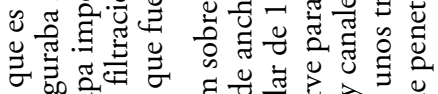

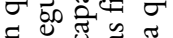
5

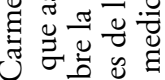
S)

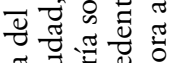

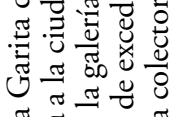

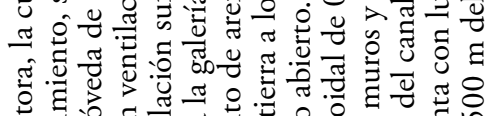

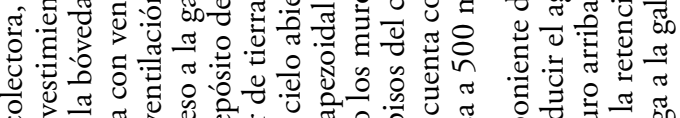

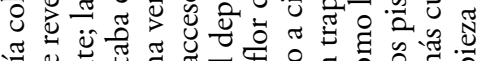

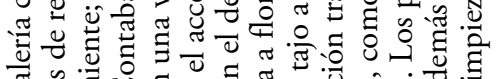

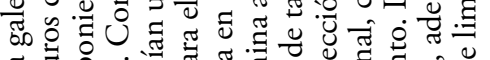

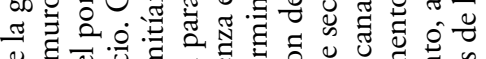

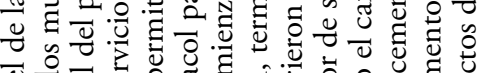

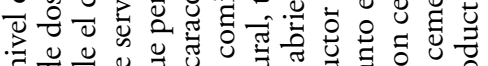

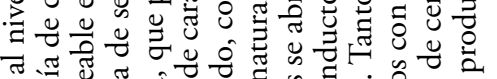

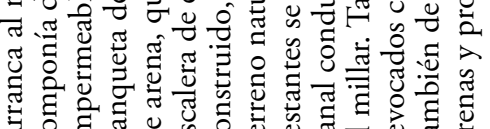

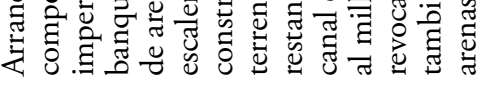

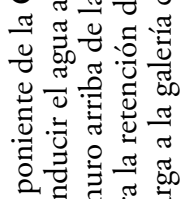

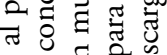

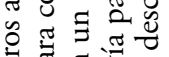
政

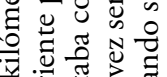

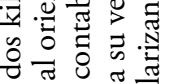

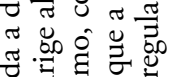

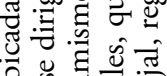
घ N

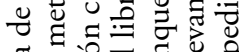

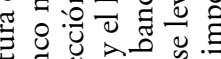
त

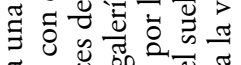
흔 焉政.

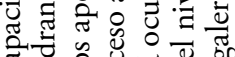

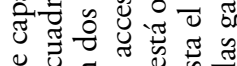

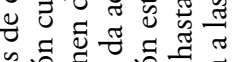
ค : 엉 光 ๘ 壳

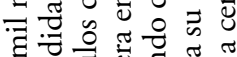
느 ప थ

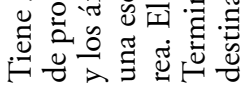

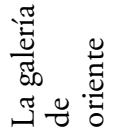

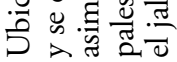

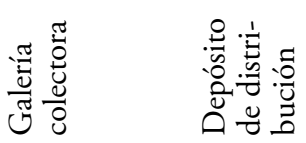

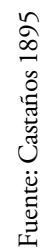


Hacia el sur y hacia el norte, se trazaron las galerías filtrantes, con una pendiente de una al millar para el canal de conducción y la galería que se conduce al oriente que se dirige a la ciudad, y quedaron de la siguiente manera, véase cuadro 6 .

Dichas obras lograron grandes cantidades de agua para abastecer a la ciudad, de acuerdo a la medición que se realizó en septiembre de 1896: las del valle del Colli depositadas en el "Caracol Buzeta", 52 litros por segundo, o sea, 4,492,800 litros por día; el Depósito de Arenas dio 40 litros por segundo o 3,456,000 litros por día, superando con mucho a las registradas en 1893. La obra de Castaños se diferenciaba a la de Buzeta, en que él no construyó una serie de pozos, sino que buscó las aguas subterráneas para llevarlas a un sólo canal para que se reunieran en el colector y de ahí fluyesen a la ciudad (Severo Díaz en Jímenez 1992).

Castaños al igual que el oidor Camacho no siguen la línea de Los Colomos señalada por Buzeta, donde se encuentran una serie de manantiales que aún no habían sido explotados. Aunque esto podría deberse a que era la primera fase de su proyecto y a que renuncia en agosto de 1896. Algunos señalan que por conflictos, ya que el gobernador Curiel le pidió un informe de las obras. Severo Díaz señala que se debió a que fue por falta de fondos, lo cierto es que para el proyecto de Los Colomos se llamó al ingeniero don Agustín Pas$\mathrm{cal}$, antiguo director del observatorio astronómico y meteorológico del estado de Jalisco, autor de una carta geográfica, para que llevara a cabo dicho proyecto.

Consideraban que pese a los recursos hídricos obtenidos a partir de las obras realizadas por Castaños, no serían suficientes, por lo que el Congreso del Estado autorizó al gobernador Curiel, el 18 de abril de 1898, contratar con el señor Geo S. Cook, de Chicago, un préstamo por $\$ 1,500,000$ pesos en oro americano, al cual se le suma la cantidad de $\$ 800,000$ pesos, los cuales serían destinados únicamente al saneamiento de la ciudad de Guadalajara, abastecimiento de agua potable, construcción del mercado Libertad, amortización de la deuda del estado, construcción de dos escuelas y finalmente para la edificación de talleres de Penitenciaría, así como el departamento destinado a los reos excarcelados (Jiménez 1992). En el periodo del 
Cuadro 7. Infraestructura de las galerías filtrantes del ingeniero Pascal (1896)

Galerías superficiales

Los Colomos

Incluía los arroyos de: al sur de Zapopan en el barranco profundo el arroyo de la Campana, al sureste se une el arroyo de Chochocastli y al este el de Los Colomos, de agua tibia. De este arroyo hay otra fuente de agua conocida por el "Aguacero". Recordando que éstos se encontraban más abajo del nivel del centro de la ciudad, pero las condiciones tecnológicas eran diferentes a las que había en la época colonial.

Sistema de Contaba con bombas eléctricas que permitieron bombear bombeo el agua hacia el colector Curiel casi a flor de tierra de donde se impulsaba hacia la torre de vigía para llegar al acueducto nombrado "Porfirio Díaz", mejor conocido hoy como Acueducto Castaños.

Salón de Además de otro mejor equipado para el maquinista.

máquinas

Casa y salones Casa para empleados y salones de banquetes y jardines.

Colector Curiel Casi a flor de tierra por lo que fue necesario ponerle canceles artísticos y darle disposición para que el público viera la cascada que formaban los chorros de agua recogida.

Tanques al aire El agua también a la vista del público se tomaba por las libre bombas para impulsarlas hacia la torre del vigía.

Torre del vigía De aquí se envía el agua recabada en los tanques de Los Colomos por el acueducto Porfirio Díaz.

Acueducto Porfirio Díaz

Atraviesa la barranca Ancha de los Chorros que anteriormente se había considerado como uno de los grandes obstáculos para poder utilizar el agua de Los Colomos, dicha obra se conectaba al norte de las galerías del "Colli" de Castańos con las de Colomos. El acueducto se construyó con una longitud de $294 \mathrm{~m}$, con 45 arcos de medio punto con $5.31 \mathrm{~m}$ y dos arcos pequeños con diámetro de $2.02 \mathrm{~m}$ (Jiménez 1992).

Fuente: Jiménez 1992.

gobernador Curiel se inicia una nueva modalidad en la organización y presupuestación para la construcción y ampliación de obras para conducir el líquido a la ciudad por medio de contratación de créditos, por lo que es posible llevar a cabo el proyecto presentado por el ingeniero Pascal, que consistía en la captación e introducción del 
Fото г. Puente canal "Porfirio Díaz" sobre la Barranca ancha o Arroyo de los Chorros. Los puente-canal se suelen llamar acueductos

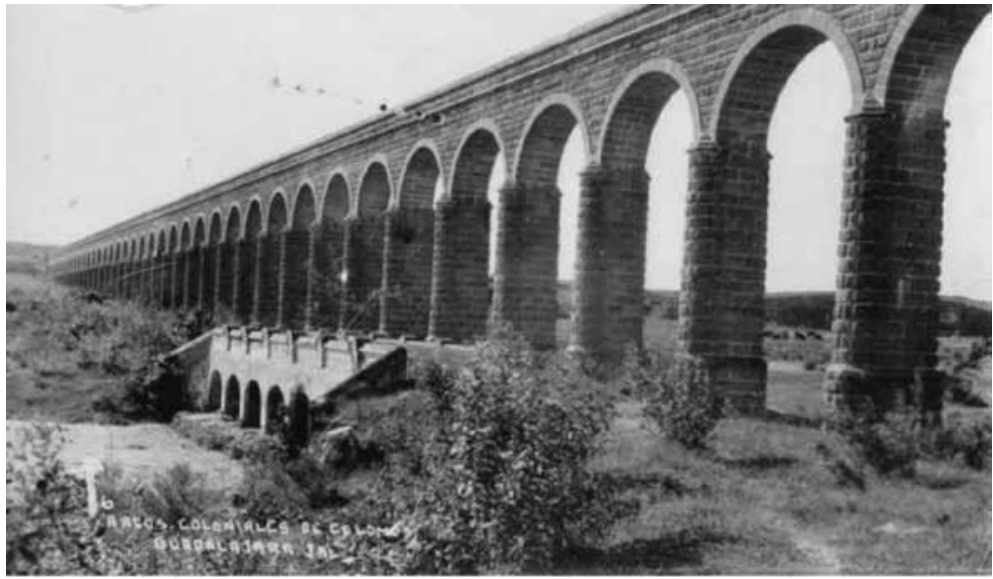

Fuente: S/D.

agua en galerías casi superficiales captando el agua de los veneros antes de derramarse a los arroyos en la cercanía de Los Colomos.

Las obras de los ingenieros Castaños y Pascal se realizaron antes de terminar el siglo XIX, con un costo de 912,710 pesos. Aprovecharon las aguas de Los Colomos a partir de galerías, acueductos, arenero y tanque de distribución; además se puso nuevamente en servicio el Manantial del Agua Azul (por bombeo), se concluyeron las obras de conducción de agua de San Andrés y las de San Ramón (al oriente de la ciudad) como se señaló de manera detallada en párrafos anteriores. También se decidió entubar el río San Juan de Dios en 1908 , por los problemas de contaminación que venía presentando desde hacía casi cincuenta años atrás.

El gobernador Curiel atribuye gran importancia a Los Colomos, adquiriendo de particulares por compra-venta 248 hectáreas para proteger los manantiales donde se construye una de las más modernas fuentes de abastecimiento de agua para la ciudad, además se forma un bosque, a la vez de embellecer el lugar con más de $30 \mathrm{mil}$ árboles de diferentes especies, esta obra contribuye a la producción de aguas subterráneas (Estrada Godínez 2008). Así mismo, adquie- 
Fото 2. Galerías filtrantes de Guadalajara, 1949

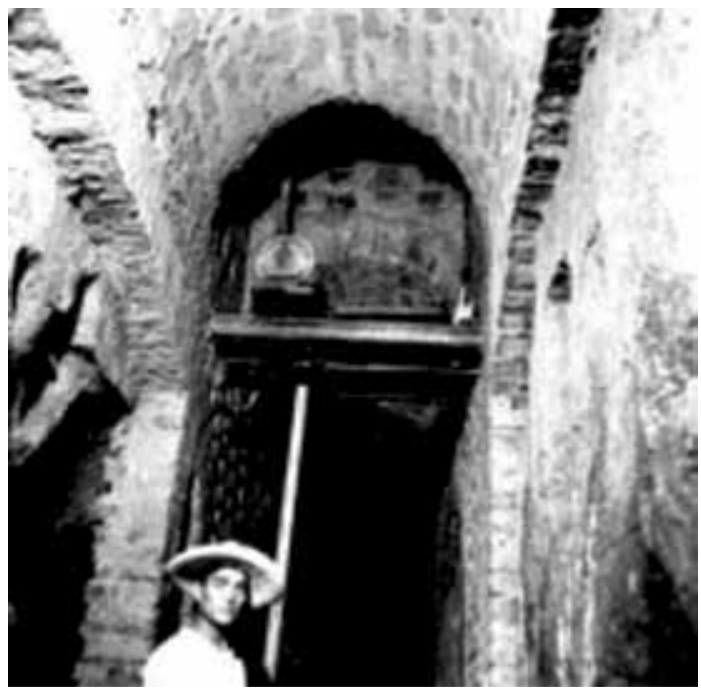

Fuente: S/D.

ren también los terrenos donde se ubican los manantiales de San Rafael, San Andrés y La Purísima y se inicia la introducción de estos volúmenes a la obra iniciada por el obispo Aranda, bajo la dirección del ingeniero Agustín Bancalari, suman con ello al suministro de agua 82 litros por segundo (Martínez 1988). Con estas obras, Guadalajara resolvió por algunos ańos su problema de abastecimiento de agua, además permitió construir "hermosos jardines y parques", el parque de San Rafael y el de Agua Azul (Jiménez 1992).

Las galerías filtrantes de fray Pedro Buzeta, marcaron por más de 200 años el modelo de captación, almacenamiento, conducción y abastecimiento de agua para la ciudad, lo que permitió conectar los diferentes afluentes subterráneos para satisfacer la demanda de sus habitantes.

La ubicación de las galerías filtrantes de Buzeta-oidor Camacho, Castaño y Pascal, al poniente del río San Juan de Dios, y las del obispo don Diego de Arana, al oriente de este río, se pueden apreciar en el plano 5, suman un total de nueve líneas de galerías, las cuales han quedado dentro de la actual zona metropolitana de Guadalajara y en algunos casos bajo los edificios o casas de esta gran ciudad. 


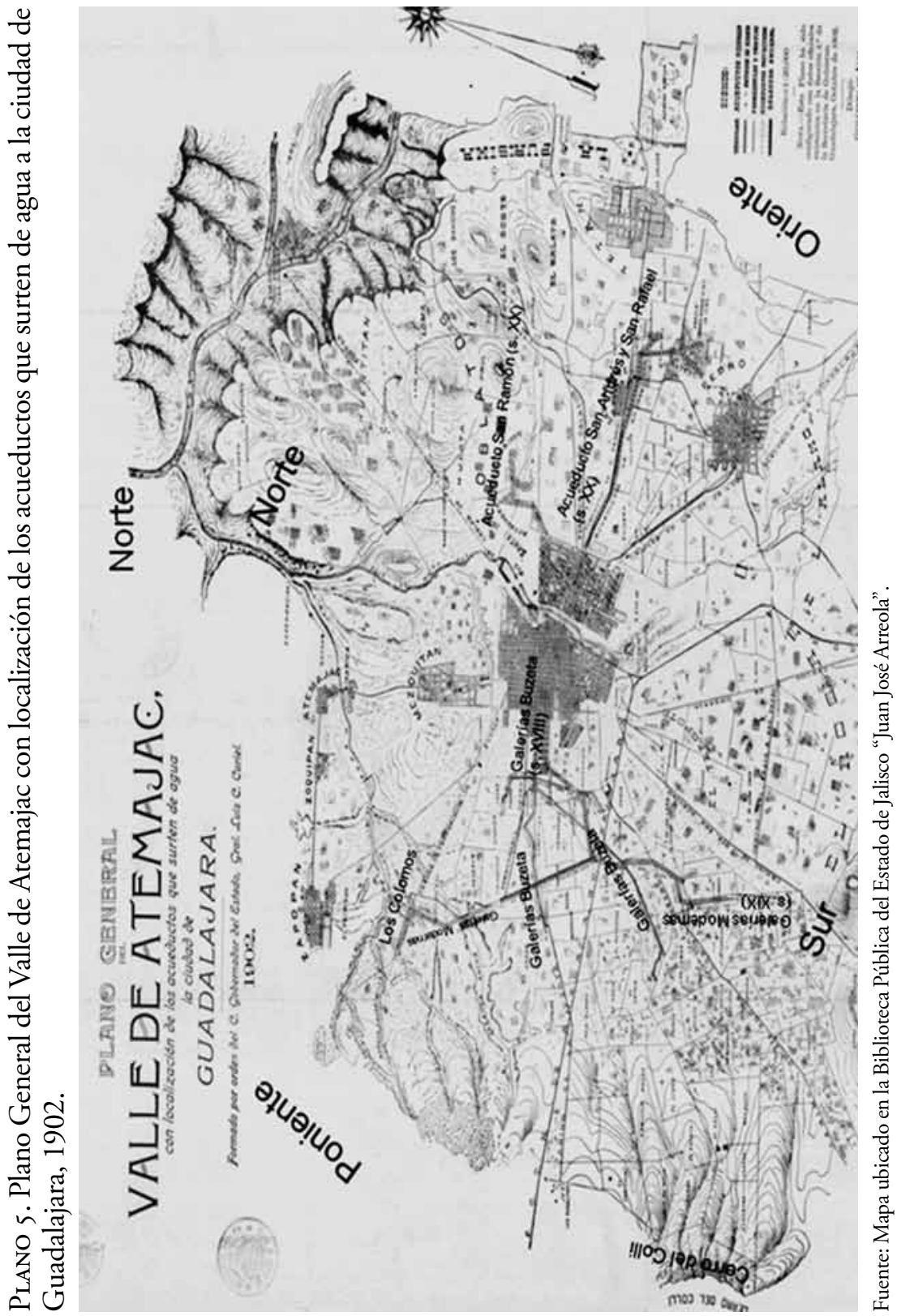


La ciudad inicia el siglo xx con nueve galerías filtrantes, tanto para la captación y conducción de agua, así como cañerías para la distribución de agua colectiva a través de las fuentes públicas, iglesias, instituciones de gobierno, asimismo, casas particulares. Además de las aguas de los manantiales de Agua Azul, que junta sus aguas en el Caracol para aumentar sus caudales, además de las de San Ramón, San Rafael, San Andrés, todas ellas permitieron un abasto de 232 litros por habitante (Jiménez 1992).

En 1910 se inicia la Revolución, proceso que interrumpe la generación de servicios públicos por más de dos décadas. En 1929, Guadalajara contaba con alrededor de 175,000 habitantes y el agua disponible era de 222 litros al día por habitante.

CuAdro 8. Fuentes de abastecimiento de agua de Guadalajara, 1929

\begin{tabular}{lc}
\hline Fuentes & Aforo \\
\hline Galerías filtrantes (Buzeta y Castaños) & S/D \\
Galería de los Los Colomos/Ing. Pascal & $288 \mathrm{lps}$ \\
Manantiales del Agua Azul & $40.5 \mathrm{lps}$ \\
Galerías filtrantes de San Rafael y San Andrés & $31.8 \mathrm{lps}$ \\
Galerías de San Ramón & $1.1 \mathrm{lps}$ \\
Total & $461.4 \mathrm{lps}$ \\
\hline
\end{tabular}

Fuente: Martínez Réding, 1974.

A partir de 1933 se estabiliza la situación del país, además de presentarse cambios significativos en la tecnología que impactan de manera importante la reutilización de las antiguas fuentes de abastecimiento a través del uso de motores eléctricos para el bombeo de sus aguas, así como la perforación de nuevos pozos a más de 100 metros de profundidad como: Agua Azul, Colonia moderna, el Rastro. En el caso de Los Colomos se instalan los nuevos motores en la planta de bombeo. Todas ellas contribuyen a incrementar el aforo de agua a 492 litros por segundo, sin embargo, éste resulta insuficiente debido al crecimiento poblacional, pues, para 1947 se contaba con una población de 320,000 habitantes que corresponden a 133 litros por habitante al día. 
Algunas fuentes de abastecimiento han desaparecido y otras al parecer conducen la poca agua que producen a otras redes de suministro y sólo mantienen su nombre, pues son absorbidas por otros sistemas al insertarse en los nuevos acueductos. Otros caso son las galerías de San Rafael, San Andrés, San Ramón que dejaron de conducir el agua al Hospicio y barrio de San Juan de Dios que han quedado disminuidas y la galería de San Rafael sólo abastecía al parque que lo alberga. ${ }^{8}$

No es el caso de las galerías de Castaños y Pascal (agua de los arroyos y manantiales de Los Colomos), que aun cuando forman parte del nuevo sistema de abastecimiento de agua potable y alcantarillado (SIAPA), siguen en funciones. En el caso de las galerías sur de Castaños, encontramos que la caja de aguas ubicada en Lerdo de Tejada y Agustín Yánez aún recibe agua del Colli, pero es utilizada para el riego de áreas públicas. Las galerías de Buzeta están aún más desdibujadas de la memoria tapatía. El desuso de este sistema que por muchos ańos fue la principal fuente de abastecimiento de agua de Guadalajara se dejó de lado, ya que la laguna de Chapala, a través de río Santiago, resultaba ahora más fácil y menos costosa que el mantenimiento de esta infraestructura para solventar el crecimiento urbano poblacional que ha venido presentando la ZMG y quedó en el olvido el sistema de captación de agua que alimentaba los mantos freáticos de la ciudad, ahora han quedado bajo grandes lozas de pavimento.

\section{El IMPACTO DE LA CONSTRUCCIÓN DE LA INFRAESTRUCTURA} HIDRÁULICA EN LAS ZONAS DE EXTRACCIÓN Y SU SUSTENTABILIDAD

A casi trescientos años de la construcción de galerías filtrantes de Buzeta y a cien años de las de los ingenieros Castańos y Pascal para la extracción del agua, vía el uso de aguas phreaticas y subterráneas ${ }^{9}$

${ }^{8}$ Entrevista a un trabajador del Servicio del Agua Potable y Alcantarillado (SIAPA), encargado de los pozos ubicados en el parque de San Rafael, en la colonia San Andrés, Guadalajara, Jalisco.

${ }^{9}$ Phreaticas y subterráneas no las utilizamos como sinónimo ya que Castaños hacía una diferenciación de ellas por los niveles en que éstas eran captadas para su conducción y almacenamiento. 
algunas de ellas siguen funcionando -como se señaló en el apartado anterior-, en el caso concreto de las galerías de Los Colomos, éstas abastecen actualmente a más de 45 mil habitantes de las colonias ubicadas al poniente de la ZMG, es decir, a casi $50 \%$ de las que abastecía en su inicio (107,000 habitantes en 1898). Con lo cual se puede ver la utilidad en su sistema de captación y conducción.

Se considera actualmente, que la construcción de las galerías filtrantes están formando grietas en la zona poniente de la ciudad de Guadalajara por las condiciones actuales como se encuentra dicha infraestructura, dado a que se les ha dado poco mantenimiento, en especial a las de Buzeta y la prolongación de éstas realizada por el oidor Camacho, por desconocer su ubicación bajo la nueva urbe metropolitana, lo cual no permite su aprovechamiento, ya que pueden estar generando fugas de agua por los socavones ${ }^{10}$ que se hubieran realizado para drenarlas y proteger las galerías de posibles inundaciones. Además, de que algunas podrían haber sido dañadas a partir de la construcción de las nuevas obras de la ciudad como son los pasos a desnivel ubicados en las avenidas López Mateos, Américas, Hidalgo, que han presentado abundancia de agua en su proceso de construcción.

Asimismo, no son consideradas importantes en el nuevo sistema de abastecimiento de agua a la ZMG por los supuestos bajos niveles que aportan, al olvidar lo que señalaba anteriormente (Buzeta, el ingeniero Castańos y López Cotilla y actualmente varios investigadores de la Universidad de Guadalajara) que existía suficiente agua para abastecer por bastante tiempo a la creciente ciudad de Guadalajara o que las condiciones de estos acuíferos subterráneos han sido modificados por la falta de captación de lluvias, la cual era una fuente importante de producción de agua abundante y de bue-

${ }^{10}$ De acuerdo con Palerm (2004), la tecnología utilizada para realizar las galerías filtrantes están basadas en la construcción de minas, por lo que se conocen como "minas de agua”, por lo que éstas también podrían presentar problemas de inundación, lo que fue resuelto bajo las mismas estrategias: abandonar la mina, extraer el agua con malacate (un sistema de elevación del agua accionado por caballos o mulas) o hacer una contramina, también llamada socavón, para sacar por gravedad el agua. 
na calidad como lo refería el benemérito educador López Cotilla (1842): "No podrá dudar ninguno que conozca las inmediaciones de Guadalajara y que haya observado la multitud de manantiales que en todas direcciones la circundan. Que éstos puedan abastecer la ciudad”. Que al igual que el ingeniero Castaños (1895):

Pero si no es posible saber cuál sea la capacidad de las antiguas obras, las siguientes consideraciones nos llevan a creer, que la más de aguas subterráneas es bastante para surtir a Guadalajara. El terreno que al poniente de la ciudad se extiende, desde el Puerto de Santa María, hasta las [...] [y que sólo] se ha considerado solamente un $25 \%$ de absorción, como cualidad natural del terreno del valle; $y$ no se ha tomado en cuenta el empleo de los medios que se tienen para aumentar ese tanto por ciento, deteniendo el deslizamiento de las lluvias sobre la superficie, para obligar a las aguas a penetrar a las capas porosas y aumentar así el almacenamiento. Por consiguiente, no sólo se cuenta con el acopio natural por infiltración de las lluvias, sino que, obras exteriores permitirán sin grandes dificultades, aumentar la riqueza hidráulica de las capas porosas (Castańos 1895).

Actualmente, Gleason (2007) menciona que las galerías filtrantes siguen en abastecimiento, pero que desgraciadamente están descuidadas y se están destruyendo, no obstante sus condiciones señala que de ellas se pueden obtener 0.5 metros cúbicos por segundo ya que se cuenta con un potencial de captación importante en la zona por el promedio anual de lluvias que es de $897 \mathrm{~mm}$ y un temporal que dura de mayo a octubre. Pero para reactivar este sistema, es necesario revisar las condiciones existentes de dichas obras y darles mantenimiento y de no ser útiles, por las condiciones en que se encuentran, se deben buscar otras formas para la captación de lluvias que alimenten los mantos acuíferos que están sobrexplotados.

El acuífero de Los Colomos se caracteriza por su capacidad de infiltración, dado que se encuentra bajo una capa geológica abundante de toba o pómez y donde se han desarrollado redes de galerías filtrantes de hasta seis kilómetros para alimentar dos tanques de 5,460 metros cúbicos. Todo ello permite alrededor de 400 litros por 
segundo, distribuyéndose en una amplia extensión de 17 colonias para dotar de agua a más de 45,861 habitantes, entre éstas están: Santa Teresita, Ladrón de Guevara, Mezquitán Country, Chapultepec Country, Lomas del Country, Country Club, Prados Providencia, Providencia 1, 2 y 3, Italia Providencia y Villaseñor (SIAPA 2006). Se debe reconocer incluso que no se aprovecha agua que se vierte constantemente al río Atemajac, por avenida Patria, donde corren 130 litros por segundo, es decir, 11,228 metros cúbicos al día; este líquido, de usarse con ecotécnicas, alcanzaría para abastecer a 74,855 habitantes con un gasto de 150 litros al día (Estrada 2008). Sin embargo, no habría que olvidar que el área hidrológica de Los Colomos presenta, entre otros aspectos, la siguiente problemática (Estrada 2008):

- Persistencia de irregularidades por posesión indebida de terrenos.

- Nulo resguardo y seguridad jurídica de lo que queda de terreno para uso sustentable en beneficio de la población, porción de 81 hectáreas donde pudiera surgir Colomos III en territorio de Zapopan.

- El cambio de uso de suelo potencialmente nocivo a los mantos freáticos y manantiales, al otorgar permisos de construcción para gigantescas obras, como nuevos fraccionamientos, plazas comerciales, edificios verticales de gran altura y pasos a desnivel, que hacen colapsar toda la cuenca.

- De acuerdo a los estudios geológicos presentados en el Atlas de Riesgo (1994) existen mayores amenazas en esta área de la ZMG por deslizamientos, hundimientos y sismicidad e inundaciones.

Además de la amenaza de la formación de grietas en estas zonas que pueden ser consecuencia de lo citado en los párrafos arriba sobre las obras de Buzeta y Castańos, donde hacen constante mención de los cortes a la superficie para lograr la filtración del agua de lluvia, que ocasionan el posible debilitamiento de la tierra y que han quedado bajo las grandes lozas de pavimento que no permiten su retroalimentación que produce resequedad de la tierra. Las galerías filtrantes en el subsuelo de Zapopan han provocado afectaciones de 
riesgo que evidencian poca atención y conocimiento de su ubicación por parte de las autoridades municipales.

Se señala, a su vez, que el Valle de Tesistán es un catálogo de fisuras causadas por los cambios de espesor en la materia volcánica del subsuelo, además de la intensidad de las lluvias constantes, así como la presencia de hundimientos y agrietamientos en colonias: Santa Margarita, Nuevo México, Residencial Poniente, Valle Real y la Tuzanía, entre otras que se ubican en la zona del valle de Tesistán. Por otra parte, el periódico El Nuevo Siglo de Guadalajara constató el chorro de agua limpia que corre por las grutas debajo de una escuela que, se supone por su ubicación, podría ser parte de alguna de las galerías filtrantes de Buzeta dentro del llamado Parque Hundido, en Santa Margarita, en la Escuela López Mateos ubicada en esta colonia. ${ }^{11}$

Por lo que el rescate de otras fuentes de agua podrían ser los manantiales: Colomitos, afloramientos de agua importantes en la unidad deportiva Tucson en el norte de la ciudad; al sur el vaso del Deán, con los cuales se podría recuperar un metro cúbico de este recurso, aguas que se desperdician, unas se van al drenaje y otras son contaminadas por los desechos de la industria, como en el caso del Deán (Gleason 2008). Por lo que, para un rescate con enfoque sustentable, Gleason sugiere lo siguiente en el cuadro 9.

Con el rescate de fuentes de agua bajo un enfoque sustentable se podría recuperar alrededor de $22.83 \mathrm{~m}^{3}$ por segundo para la ZMG, al considerar a los ocho municipios que la conforman actualmente: Guadalajara, Zapopan, Tonala, Tlaquepaque, El Salto, Juanacatlan, Tlajomulco de Zúñiga e Ixtlahuacan de los Membrillos, que cuenta con alrededor de 4,364,069 habitantes, se abastecerían 165 litros por habitante al día por encima de lo señalado para las ciudades sustentables que es de 160 litros por habitante al día. Además de no requerir nuevos embalses para su abastecimiento y se ańade una nueva cultura de los usos del agua.

11 "Galerías filtrantes, problema ignorado por la administración municipal" disponible en http://special.radioextremo.com/Noticias-Internacionales/6627.htmlSbrina, X. N. (30 de junio de 2007). 
Cuadro 9. Fuentes factibles de rescate de agua bajo un enfoque sustentable para la ZMG

Fuente

Aforo metros cúbicos por segundo por fuente

Sistemas domésticos por infiltración micro y macro 4.0 captaciones

Captación de agua de lluvia

Rescate de manantiales

Red de distribución de agua

Galerías filtrantes

Laguna de Chapala

Sistema de pozos Toluquilla-Tesistán

Sistema de Presas la Zurda-Caldero (primera fase)

Total

Fuente: Gleason 2008.

De acuerdo a lo mencionado, resulta necesario realizar una investigación más a fondo sobre lo aquí expuesto, ya que se deberán comprobar todas las probabilidades planteadas y buscarse alternativas de solución; primero para el aprovechamiento de los recursos hídricos de esta cuenca que continúa abasteciendo a una parte de la ciudad y, en segundo lugar, cuidar que no se siga dańando el ecosistema dentro y fuera de la ZMG para garantizar su sustentabilidad y medio ambiente, así como evitar riesgos por grietas dentro de las zonas urbanas.

\section{Conclusiones}

El abastecimiento de agua a la ciudad de Guadalajara y posteriormente a su zona metropolitana ha contado con una serie de fuentes de suministro para sus necesidades domésticas, agrícolas e industriales, que han conformado la región hidrológica de Guadalajara, sin embargo, el crecimiento dinámico de la ciudad por su ubica- 
ción estratégica en el occidente de México, ha enfrentado periodos de escasez como consecuencia del crecimiento poblacional y urbano al principio de su formación y posteriormente por la instalación de la industria que no le ha permitido dotar de los recursos necesarios en el corto plazo, aunado a la falta de recursos económicos suficientes, así como de la tecnología necesaria o adecuada para su extracción, conducción y distribución, además de proyectos integrales e incluyentes que permitan dotar de manera equitativa dicho recurso.

La construcción de las galerías filtrantes del hermano lego fray Pedro Buzeta fue una gran obra de ingenio y causó gran impacto en la ciudad de Guadalajara, lo que permitió el abastecimiento de agua a la ciudad por más de 200 años, si bien presentó problemas de captación de agua durante algunos periodos de tiempo, esto no se debió a la falta de recursos hídricos, sino a la falta de recursos económicos, pues, cuando se le daba continuidad a su proyecto, la ciudad volvía a calmar su sed; ya que los proyectos que le precedieron se manejaron bajo el mismo principio de aprovechamiento de las aguas subterráneas de su entorno, pero además de la producción de agua a partir del almacenamiento de las aguas pluviales que favorecen mucho a la ciudad y que ahora causan estragos y se consideran de riesgo por su volumen, además de que éstas no penetran los acuíferos, sino que se desperdician en los drenajes.

Otro elemento importante fue el de generar los espacios adecuados para la producción de agua como lo fueron la compra de terrenos para proteger los manantiales y producir agua en la zona para alimentar los mantos acuíferos como en el parque Los Colomos en el poniente del río San Juan de Dios (ahora Calzada Independencia) y el Parque San Rafael al oriente de este río. Lamentablemente hoy, el espacio de Los Colomos se ve reducido en su área de influencia y con ello están amenazados los manantiales existentes que dan vida a las galerías que construyeron los ingenieros Castańos y Pascal bajo las órdenes del gobernador Luis Curiel. Repensar la ciudad desde un enfoque sustentable no es una moda discursiva, es una necesidad urgente para la sustentabilidad de las ciudades y el derecho humano al agua de sus habitantes. 
Bibliografía

Atlas de Riesgos de la Ciudad de Guadalajara Patrocinadores, Guadalajara, Gobierno del Estado de Jalisco, Comisión Estatal de Ecología, Universidad de Guadalajara, 1994.

Buzeta, Pedro Antonio, "Carta de Fran Pedro Antonio Buzeta al Señor Don Juan Rodríguez de Albuerne del Consejo de su Magestad su Oidor de la Real Audiencia de la Ciudad de Guadalajara y Superintendente Genera por su Magestad de la Saca de Agua mina y conducción”, anexo en José Cornejo Franco, $\mathrm{Pa}$ peles tapatios, Imprenta Universitaria, Guadalajara, 1942 [1733].

Castaños, Gabriel, Apendice inI: "Abastecimiento de aguas de Guadalajara, las obras del Colli, Apuntes del Ing. Gabriel Castaños", en Capitulos de historia de Guadalajara, Guadalajara, Ayuntamiento de Guadalajara [1895] (1992),

Cамасно, Francisco, Informe dado al Excmo. Señor Virrey de Nueva España por el Oidor D. Francisco Camacho, Comisionado de la obra de introducción de agua potable a la ciudad de Guadalajara, Guadalajara, Tipografía del Gobierno, Biblioteca Pública del Estado de Jalisco "Juan José Arreola” de la Universidad de Guadalajara, 1886.

Cornejo Franco, José, Papeles Tapatios, Introducción del agua a Guadalajara, Guadalajara, Imprenta Universitaria, 1942.

Estrada Godínez, J., Fernando, "Los Colomos en la encrucijada de la supervivencia, II parte", La Jornada, jueves 16 de octubre de 2008, 2008.

Gleason Espíndola, José Arturo, "Alternativas para abastecernos de agua”, en La Gaceta $U$ de G, 2007, 485.

GonzÁlez García, Ana Rosa, "Estrategias y control del agua en Guadalajara, siglo xIx. El caso de las industrias textiles", Salvador Peniche Camps y Manuel Guzmán Arroyo, coords., en Estudios de la cuenca del río Santiago: un enfoque multidisciplinario, Guadalajara, Universidad de Guadalajara-Cucea, 2010.

Jiménez Pelayo, Águeda, “Agua para Guadalajara, desde su fundación hasta 1902", en Capitulos de historia de la ciudad de Guada- 
lajara, Guadalajara, Ayuntamiento de Guadalajara, 1992, 72-87.

López Cotilla, Manuel, Historia de la introducción de agua en Guadalajara desde su fundación hasta la fecha, Guadalajara, 1842. López Moreno, Eduardo, La cuadrícula en el desarrollo de la ciudad Hispanoamericana, Guadalajara, Universidad de Guadalajara, Instituto Tecnológico de Estudios Superiores de Occidente, 2001. Martínez Réding, Fernando, Agua para Guadalajara, Patronato de los Servicios de Agua y Alcantarillado de Guadalajara, Guadalajara, 1974.

, Agua para la zona metropolitana de Guadalajara 1983-1988, México, Sistema Intermunicipal de los Servicios de Agua Potable y Alcantarillado (SIAPA), 1988.

PAlerm-Viqueira, Jacinta, "Las galerías filtrantes o qanat en México; Introducción y tipología de técnicas", en Agricultura, Sociedad y Desarrollo, 1:2, 2004, 133-135.

Placencia Suárez, Carlos y José de Jesús Díaz Torres, “Desarrollo de grietas en el Fraccionamiento Prados de Nextipac, Jalisco, Municipio de Zapopan”, GEOS, vol., 25, núm. 2. 2005,

Torre Villar, Ernesto de la, "Religión y Ciencia en el México Colonial”, en Anuario de Historia de la Iglesia, vol. xII, Pamplona, Universidad de Navarra, 2003, 255.

Torres Rodríguez, Alicia, "Abastecimiento de agua a la Zona Metropolitana de Guadalajara, Desarrollo urbano y conflictos por el agua”, 1952-2008, Tesis doctoral, Guadalajara, Universidad de Guadalajara, 2009.

Villa GordoA, José, "Acueductos, fuentes, hidrantes, baños y puentes”, Guía y álbum de Guadalajara para viajeros, vol. IX, Guadalajara, Cámara Nacional de Comercio de Guadalajara, 1980.

\section{ENTREVISTAS}

Entrevista a un trabajador del SIAPA, encargado de los pozos ubicados en el Parque de San Rafael, en la Colonia San Andrés, Guadalajara, Jalisco. 
Página de internet

"Galerías filtrantes, problema ignorado por la administración municipal" htmlSbrina, X. N. (30 de junio de 2007) http://special. radioextremo.com/Noticias-Internacionales/6627.

Fecha de ReCepción del artículo: 22 de julio de 2011 FECHA DE RECEPCIÓN DE LA VERSIÓN FINAL: 30 de enero de 2013 